Estudios Constitucionales, Año 14, No 2, 2016, pp. 101-142

ISSN 07180195

Centro de Estudios Constitucionales de Chile Universidad de Talca

"Control de convencionalidad interno y jueces locales: un planteamiento defectuoso"

Max Silva Abbot

\title{
CONTROL DE CONVENCIONALIDAD INTERNO Y JUECES LOCALES: UN PLANTEAMIENTO DEFECTUOSO*
}

\author{
INTERNAL CONTROL OF CONVENTIONALITY AND LOCAL JUDGES: \\ A FAULTY APPROACH
}

\author{
Max SiLVA Aвbot ${ }^{* *}$ \\ Universidad San Sebastián \\ max.silva@uss.cl
}

RESUMEN: Las exigencias establecidas por la Corte Interamericana de Derechos Humanos por vía jurisprudencial para el ejercicio del control de convencionalidad interno, asi como las reflexiones que la mayor parte de la doctrina ha hecho sobre la materia, presentan varios problemas, tanto si gracias a su utilización se produce una inaplicación de la norma doméstica o una interpretación que la armonice con las disposiciones internacionales. Dichos problemas afectan a la labor de los jueces nacionales y a la propia implementación de este control, al punto que podrian llegar a hacerlo relativamente ilusorio. El presente estudio ofrece un análisis orgánico de estos inconvenientes desde el interior de los ordenamientos juridicos afectados, puesto que, por regla general, la teoría del control de convencionalidad ha sido elaborada fundamentalmente desde la óptica del Derecho Internacional.

ABSTRACT: The exigencies that the Inter-American Court of Human Rights has established through its jurisprudence to exert the internal control of conventionality, as well as the reflections that most of the doctrine has done on the subject, show various problems, whether if following such control produces the inapplicability of the domestic rule or if an interpretation harmonizes the domestic and the international law. Such problems affect the work of national judges as much as the implementation of said control, up to the point that it could remain illusive. This paper analyses these inconveniences in an organic way from within the affected legal orders, given that the theory of conventionality control has been generally elaborated from the fundamental optic of international law.

PALABRAS CLAVE: Control de convencionalidad, Jueces internos, Competencias y regulaciones procesales correspondientes, Interpretación, Principio pro homine.

KEYWORDS: Control of conventionality, Local Judges, Jurisdiction and procedural regulations, Interpretation, Pro homine principle.

\footnotetext{
* Trabajo recibido el 22 de diciembre de 2015 y aprobado el 7 de septiembre de 2016.

** Licenciado en Ciencias Jurídicas y Sociales por la Universidad de Chile (1993). Doctor en Derecho por la Universidad de Navarra (2006). Profesor de Filosofía del Derecho, Fundamentos Filosóficos del Derecho e Introducción al Derecho, Universidad San Sebastián, sede Concepción. Director del Departamento de Ciencias del Derecho de la misma universidad.
} 


\section{INTRODUCCIÓN}

El presente trabajo tiene por objeto analizar el llamado "control de convencionalidad interno", esto es, el que de acuerdo a lo establecido por la jurisprudencia de la Corte Interamericana y por la doctrina, debieran realizar los jueces de un país, pero visto desde la perspectiva de los ordenamientos jurídicos nacionales afectados por el mismo.

La razón del enfoque propuesto radica en que, a nuestro juicio, la manera en que ha sido planteado el control de convencionalidad en sede interna, genera una serie de problemas e incógnitas de cara a la actuación de los jueces nacionales. Incluso, si se sigue al pie de la letra el modo en que algunos pretenden su implementación, por momentos se hace difícil llevarlo a la práctica, todo lo cual podría hacer relativamente ilusoria su vigencia. Con todo, debe advertirse que algunos de estos problemas son, al menos todavía, hipotéticos.

Para lo anterior, primero se mencionarán las principales características del control de convencionalidad, para luego ir abordando, de la mano de esta doctrina, algunos de los problemas que, a nuestro juicio, origina su implementación tanto para los jueces domésticos como para su propio funcionamiento. También es necesario señalar que por razones de espacio, casi no se cita jurisprudencia de la Corte.

El enfoque que se utilizará será exclusivamente formal, esto es, apuntará al funcionamiento del control de convencionalidad en sí mismo, de manera independiente a las materias específicas o a los contenidos que pretendan aplicarse mediante este mecanismo en cada caso. Por igual razón, tampoco se hará referencia a ningún orden jurídico en particular, sin perjuicio que eventualmente pueda acudirse a alguna nomenclatura tomada de nuestro sistema jurídico chileno.

Finalmente, se advierte que la intención de este trabajo no es responder a los problemas que se plantearán -algunos, creemos, difíciles-, ni dar una solución a los mismos, sino más bien abrir y facilitar el debate a su respecto, a la luz de la creciente importancia que está adquiriendo el control de convencionalidad interno, así como el Derecho Internacional de los Derechos Humanos en nuestra región.

\section{Algunos aspectos a tener en Cuenta}

\section{SOBRE EL CONTROL DE CONVENCIONALIDAD}

Antes de abordar el tema de la presente investigación, se considera indispensable señalar, sin profundizar en ellas, las principales ideas esgrimidas a propósito del control de convencionalidad, a fin de establecer las coordenadas desde las cuales se originan los problemas que se plantearán más adelante. 
Un primer aspecto es que debe distinguirse entre el control de convencionalidad externo (el que hace directamente la Corte) ${ }^{1}$ y el interno (realizado por las autoridades locales) ${ }^{2}$. Es a este último al que se prestará mayor atención en este trabajo.

También debe recordarse que el control interno ha tenido un origen jurisprudencial (puesto que no se encuentra contemplado en la Convención ${ }^{3}$ ) desde el Caso Almonacid ${ }^{4}$, que ha ido evolucionando -si bien no de una manera lineal ni orgánica5 - , y se ha ampliado cada vez más ${ }^{6}$, al afectar no sólo a los jueces, incluidos los de los tribunales constitucionales, sino también a los poderes Ejecutivo y Legislativo ${ }^{7}$, así como a las instancias democráticas ${ }^{8}$. En este trabajo sólo se abordará respecto de los primeros, quienes debieran realizarlo "ex officio entre las normas internas y la Convención Americana, evidentemente en el marco de sus respectivas competencias y de las regulaciones procesales correspondientes" 9 .

En tercer lugar, que para la aplicación del control de convencionalidad, el juez local tendría dos opciones: intentar una armonización entre ambos órdenes normativos ${ }^{10}$ (lo que se ha llamado control "débil"11), si bien se ha señalado que existe una "presunción de convencionalidad" 12 ; y en caso de una abierta incompa-

1 Binder (2010), pp. 169-172; CAstilla (2014), pp. 167-168; Hitters (2009), pp. 110-112 y 118-119.

2 García Ramírez (2011), pp. 124-131; Nogueira (2012b), pp. 1168-1170 y 1185-1196; Ferrer MacGregor (2014), pp. 237-239; Hitters (2009), pp. 110-119; Sagüés (2010), pp. 118-121.

3 García Ramírez (2011), pp. 144-145; Aguilar (2012), pp. 725-727; Dulitzky (2015), pp. 50-52 y 54-55; García Pino y Contreras (2014), pp. 217-219; Mejía (2014), pp. 136-137.

4 Corte IDH, Caso Almonacid Arellano vs. Chile (2006), párr. 124.

5 Castilla (2014), pp. 152-158; Mejía (2014), pp. 121-138; García Pino (2014), p. 371.

6 Hitters (2008), p. 147; García Pino y Contreras (2014), pp. 217-218; Henríquez Viñas (2014), p. 123.

7 Ferrer Mac-Gregor (2014), p. 238; Hitters (2013), p. 705; Rey Cantor y Rey Amaya (2014), p. 240; Becerra y Miranda (2013), p. 21.

8 Corte IDH, Caso Gelman vs. Uruguay (2011), párr. 238-240; Corte IDH, Caso Gelman vs. Uruguay. Supervisión de cumplimiento de sentencia (2013), párr. 69 (y nota 48). Comentan esto BAZÁn (2012), p. 30; IbÁÑez Rivas (2012), pp. 103-104 y 109-113; NaSH (2013), pp. 498-499; Mejía (2014), pp. 134-135.

9 Corte IDH, Caso Trabajadores Cesados del Congreso (Aguado Alfaro y otros) vs. Perú (2006), párr. 128.

10 Caballero Ochoa (2011), pp. 109-112 y 120-122; Contesse (2013), pp. 10-11; Rey Cantor (2008), p. 226; SAGÜÉS (2003), pp. 215-216.

11 Contreras (2012); Contreras (2014), pp. 237-238, 253, 257, 261-263 y 265-266.

12 Sagứés (2010), p. 131; SAgứés (s/f a), p. 466; Sagứés (s/f b), p. 385. 
tibilidad, dejar de lado la normativa local y aplicar la disposición internacional13 (control "fuerte"14).

En cuarto lugar, que de acuerdo a cierta jurisprudencia y doctrina, existiría un efecto erga omnes de la llamada res interpretata de las sentencias de la Corte ${ }^{15}$.

Finalmente, que los jueces internos son los primeros llamados a aplicar la Convención Americana ${ }^{16}$, a fin de dar un efecto multiplicador a las decisiones de la Corte $^{17}$, para que su labor sea realmente subsidiaria ${ }^{18}$-sin perjuicio que ella tenga la última palabra ${ }^{19}$, al pretender ser una especie de tribunal constitucional o de casación continental ${ }^{20}$ - y contribuir así a lograr la consolidación de un ius commune interamericano ${ }^{21}$.

Estas son, pues, las coordenadas que serán usadas como hipótesis de trabajo para los problemas que se analizan en este estudio.

Ahora bien, todo lo dicho respecto de la aplicación del control de convencionalidad conlleva mayúsculas modificaciones en cuanto a la manera en que deben actuar los jueces locales. Sin embargo, pese a esta honda transformación, hasta ahora se echa en falta un análisis más detenido de dicho fenómeno desde la perspectiva de los propios derechos nacionales afectados. Es esto lo que hace sospechar que el notable desarrollo jurisprudencial del control de convencionalidad

13 Londoño (2010), p. 811; Rey Cantor (2008), pp. 261-262; Ferrer Mac-Gregor, Voto Razonado en Corte IDH, Caso Gelman vs. Uruguay. Supervisión de cumplimiento de sentencia (2013), párr. 83-86.

14 Contreras (2012); Contreras (2014), pp. 237-238, 253, 257, 261-263 y 265-266.

15 Corte IDH, Caso Gelman vs. Uruguay. Supervisión de cumplimiento de sentencia (2013), párr. 67, 69, 71 y 102. De manera un poco vaga, Corte IDH, Caso López Lone y Otros vs. Honduras (2015), párr. 307. También se alude a lo anterior en Corte IDH. Derechos y garantías de niñas y niños en el contexto de la migración y/o en necesidad de protección internacional. Opinión Consultiva OC-21/14 de 19 de agosto de 2014. Serie A No 21, párr. 31. Comentan esto, Ferrer Mac-Gregor, Voto Razonado en Corte IDH, Caso Cabrera García y Montiel Flores vs. México, párr. 52, 63 y 79; Ferrer Mac-Gregor Voto Concurrente en Corte IDH, Caso Liakat Ali Alibux vs. Suriname (2014), párr. 86; Hitters (2013), pp. 695-710; Becerra Ramírez (2009), p. 303; García Ramírez (2011), pp. 128-129; Meier (2011), pp. 334 y 371; Pereyra (2011), pp. 167 y 173.

16 Casal (s/f), título 2 a; Dulitzky (2015), pp. 48 y 76; Binder (2010), pp. 172-173.

17 Dulitzky (2014), p. 552; Ferrer Mac-Gregor (2010), pp. 187-188; Ferrer Mac-Gregor, Voto Razonado en Corte IDH, Caso Cabrera García y Montiel Flores vs. México (2010), párr. 86.

18 Ferrer Mac-Gregor (2014), p. 240; Becerra Ramírez (2009), pp. 295-296; Paúl (2013), p. 333; Santiago (2009), pp. 118-119; Mora Méndez (2012), p. 234.

19 Sagưés, (2014b), p. 18; Rodríguez Morelión (2009), p. 360; Caballero Ochoa (2011), p. 133.

20 Binder (2010), pp. 169-170; Dulitzky (2015), pp. 64-65; Juliano (2009).

21 Dulitzky (2014), p. 548; García Ramírez (2011), p. 127; Hitters (2008), nota 98 (p. 153). 
interno, así como la abundante doctrina que ha surgido a su sombra, han sido realizados sobre todo desde la perspectiva del Derecho Internacional. Lo anterior no quiere decir que no se hayan hecho interesantes reflexiones sobre cómo aplicar y los efectos que en el ámbito interno tendría este control; sin embargo, al menos hasta donde hemos podido investigar, se requiere de un análisis más orgánico desde dentro de los ordenamientos jurídicos locales y que vincule los diversos alcances que pretende tener, a fin de estudiar con más detalle cómo se aplicaría dicho control y las consecuencias que podría generar, de llevarlo a cabo tal como lo propone la Corte y buena parte de la doctrina.

\section{El CONTROL DE CONVENCIONALIDAD QUE DEBIERAN HACER LOS “JUECES INTERAMERICANOS”}

Un primer problema que surge, a nuestro juicio, es que desde el Caso Almonacid, la Corte ha otorgado una función nueva a los jueces nacionales, al ordenarles realizar, incluso de oficio, el control de convencionalidad ${ }^{22}$. De hecho, a tal punto ha llegado lo anterior, que abundante doctrina ha comenzado a llamarlos "jueces interamericanos"23.

En efecto, con la instauración del control de convencionalidad interno, la Corte Interamericana estaría danto nuevas atribuciones a los jueces locales -al margen de si se aplica en su versión fuerte o débil-, lo cual viola el principio de legalidad, propio del Derecho Público, razón por la cual existiría una investidura irregular a este respecto.

Es decir, aun cuando algunos autores consideren que el control de convencionalidad ya era una realidad desde antes del Caso Almonacid, o incluso que ha existido siempre de manera implícita, fundamentándolo sobre todo en los arts. 1.1, 2, 25 y 29 de la Convención Americana y en los arts. 26 y 27 de la Convención de Viena sobre Derecho de los Tratados ${ }^{24}$, debe recordarse que mucha doctrina reconoce que dicho control no se encuentra establecido en el Pacto de San José, siendo su origen jurisprudencial (mediante lo que se ha llamado una "interpre-

22 Castilla (2011b), pp. 614 y 620-624; Castilla (2013), pp. 63-64 y 93; Castilla (2014), pp. 168-169; Malarino (2011), pp. 27-29 y 57; Binder (2010), pp. 175-176; Mejía (2014), pp. 118 y 138-139; BeCERRA RojasvérTiz (2012), p. 21; ÍNIGUEZ (2014), p. 384.

23 Ferrer Mac-Gregor (2011), pp. 396 y 427-428; Carbonell (s/f), p. 80; Casal (s/f), título 2 a; Ferrer Mac-Gregor, Voto Razonado en Corte IDH, Caso Cabrera García y Montiel Flores vs. México (2010), párr. 57 y 87.

24 Rey Cantor (2008), pp. 225-262; Nogueira (2012b), p. 1175; Nash (2013), pp. 506-507. 
tación mutativa por adición”25), primeramente gracias a los votos de minoría del juez García Ramírez y luego a través de su constante ampliación en los diferentes casos en que se ha abordado, incluso para algunos de modo inorgánico, según se ha dicho ${ }^{26}$. Todo esto indica claramente, a nuestro entender, que se trata de una institución nueva, razón por la cual también lo sería la actuación que ella pretende exigir a los jueces locales. Tal vez por eso se ha dicho que

"La Corte Interamericana viene resolviendo casos contenciosos desde fines de la década de los ochenta, de modo que resulta al menos llamativo que hayan tenido que pasar casi veinte años para que 'descubriera' que sobre los jueces domésticos pesa la obligación de inaplicar leyes por el uso directo de la Convención Americana”27.

Ahora bien, una cosa que debe advertirse sobre este primer problema, es que se trata de una situación que cuesta ver a primera vista, pues al abordarse el control de convencionalidad interno, se pasa de inmediato al debate sobre cómo llevarlo a cabo. Sin embargo, una cosa es tener una competencia determinada (la facultad de ejercer este control por parte de los jueces domésticos) y otra muy diferente, si bien derivada de la anterior, el modo de realizarla. No obstante, y según se ha dicho, suele pasarse de uno a otro aspecto sin solución de continuidad, lo que aquí intentamos distinguir. En otras palabras: el control de convencionalidad pretende usar para su funcionamiento las competencias y regulaciones procesales correspondientes del control de constitucionalidad, según se verá en el siguiente epígrafe; pero, a nuestro juicio, falta lo principal: tener dichas competencias, la facultad misma. Por eso, si ella no se posee previamente (el qué), la forma de llevarla a cabo (el cómo) pierde mucho de su sentido.

Ahora bien, desde nuestra perspectiva, este requisito de legalidad tiene dos facetas: una internacional y otra nacional.

Desde el punto de vista internacional, para cumplir con el principio de legalidad, el control de convencionalidad interno debiera estar establecido expresamente en la Convención Americana (sobre todo si se toma en cuenta su enorme importancia), cosa que evidentemente no ocurre; y aunque para cierta doctrina se encontraría implícito en ella ${ }^{28}$, resulta claro que su origen y desarrollo -al

25 SAgÜés (2010), p. 132; SAGÜÉs (2012b), p. 27; SAGÜÉs (s/f a), p. 467; SAGÜÉs (s/f b), p. 384.

26 Véanse notas 5 y 6.

27 Contesse (2013), p. 4. Para estas ideas, pp. 4-5.

28 Para algunos su fundamento implícito estaría en las "medidas de otro carácter" que ordena adoptar el art. 2 del Pacto (Nogueira (2012b), p. 1172; Londoño (2010), p. 804; García Pino y Contreras (2014), p. 218). 
parecer aún inconcluso- ha sido jurisprudencial, según se ha dicho. Y, además, esta cláusula tendría que haber sido aceptada expresamente por los Estados, o al menos de manera tácita, al no formular alguna reserva a su respecto, cosa que evidentemente no ha ocurrido, al no existir dicha cláusula.

Desde el punto de vista nacional, una vez aceptado este control por los diferentes países, se debieran haber hecho las modificaciones legales internas correspondientes para llevarlo a la práctica, en virtud del art. 2 de la Convención -modificaciones no menores, dicho sea de paso-, dentro de un plazo prudencial. Ello -conviene repetirlo-, porque la previa autorización legal y/o constitucional para ejercer el control de convencionalidad interno resulta esencial, por encontrarnos dentro del Derecho Público. Ahora, como nada de esto ha ocurrido, a nuestro juicio, el control de convencionalidad interno carece de la base jurídica necesaria -internacional y nacional- para llevarse a cabo.

Esto no quiere decir que los jueces domésticos no estén obligados a aplicar el tratado como una parte más del Derecho interno, sobre todo cuando ha sido incorporado al bloque de constitucionalidad, a fin de reforzar el catálogo de derechos a proteger. Mas las facultades o competencias que tendrían en virtud del control de convencionalidad deben estar previamente autorizadas por el Derecho interno.

La anterior consideración puede reforzarse si se recuerda que el art. 2 de la Convención ordena a los Estados "adoptar disposiciones de Derecho interno", si es que los derechos garantizados por este tratado no estuvieran ya resguardados por esa normativa doméstica, al tenor del art. 1.1. De esta manera, es el propio Estado quien debe adoptar las "medidas legislativas o de otro carácter" para la tutela de esos derechos, siguiendo la huella del Pacto de San José29, todo lo cual incluso podría llevar cierto tiempo ${ }^{30}$. Mas lo importante para estos efectos es que, por expreso mandato del tratado, son los Estados los que deben acoplarse al mismo, dictando para ello las normas internas necesarias.

Ahora bien, esta adopción puede implicar tanto la derogación de disposiciones contrarias, como la expedición de normas acordes a la Convención ${ }^{31}$. Pero,

29 García Ramírez (2011), p. 146; García Sayán (2009), pp. 105-108; García Pino (2014), p. 357; Rey Cantor (2008), p. 238; Núñzz Poblete (2011), pp. 70-73; Hitters (2008), pp. 133-134; Ibáñez Rivas (2012), pp. 104-105; Ferrer MaC-Gregor (2010), pp. 184-185.

30 Rodríguez Morelión (2009), p. 378.

31 Carbonell (s/f), pp. 68-70; Castilla (2013), pp. 80-82 Dolitzky (2015), p. 60; Ibáñez Rivas (2012), pp. 104-105; García SaYÁn (2009), pp. 105-108; Hitters (2008), pp. 133-134; Hitters (2009), pp. 120 y 125; NaSh (2013), pp. 494-495; NúNez Poblete (2008), p. 354; García Ramírez (2011), pp. 146-147. 
además, parece lógico que estas nuevas normas no sólo se refieran a los derechos específicos protegidos por el tratado, sino también a "reorganizar las competencias de las autoridades para que todas puedan prevenir la violación de derechos, investigar, sancionar y reparar" 32 llegado el caso, generando así los "cambios que modifiquen las condiciones estructurales de las violaciones" 33 , a fin de que los órganos del Estado puedan actuar válidamente gracias a una investidura regular para tal efecto.

Lo importante, en suma, es que aun cuando existe doctrina que considera legítimo que la Corte dé órdenes directas a la autoridades de un país, otorgando competencias a los órganos internos como en el caso del control de convencionalidad $^{34}$ (al punto que podrían ser más amplias que las facultades que tengan a propósito del control de constitucionalidad ${ }^{35}$ ), a nuestro juicio, debe ser el propio Estado quien adopte dichas normas ${ }^{36}$, no pudiendo dar estas competencias de modo directo la Corte, al carecer de la facultad para ello ${ }^{37}$.

Es por eso no creemos que sea posible que faltando estas leyes internas (a fuer de las normas internacionales según se ha dicho), baste la sola jurisprudencia de la Corte para dar una competencia como la que conlleva el control de convencionalidad interno, por mucha "interpretación mutativa por adición" que se invoque para justificarla. Ello, no sólo porque resulta más que discutible que la Corte tenga la facultad para otorgar de manera directa este tipo de poder, según se ha dicho, sino además -y a nuestro juicio, es de la máxima importancia-, en virtud del principio de legalidad propio del Derecho Público, pues en caso contrario, la Corte estaría dándose dicha prerrogativa a sí misma ${ }^{38}$.

Finalmente, debe advertirse que varios de los restantes problemas que se analizan a lo largo de este estudio -entre otros, los restantes de este epígrafe y del

32 Carbonell (s/f), p. 69.

33 García Ramírez (2011), p. 146.

34 SAgưés (2009), p. 2; SAgứés (s/f b), p. 384; SAgứés (2010), p. 123; SAGÜés (s/f a), p. 456.

35 Mora Méndez (2012), pp. 228-229; Nogueira (2012c), pp. 64 y 127.

36 Castilla (2013), pp. 85 y nota 91 (p. 93); CAstilla (2014), pp. 165 y 168; ContesSe (2013), nota 23 (p. 11) y pp. 13 y 29-31; Castilla (2011b), p. 614; Henríquez Viñas (2009), pp. 36 y 43.

37 Castilla (2011b), p. 614; Castilla (2014), p. 165; Malarino (2011), p. 27; Binder (2010), pp. 175-176 y 187-188; MEjÍA (2014), p. 139.

38 BiANCHI (2010), pp. 4-5; Binder (2010), pp. 161, 173, 175-176 y 187-188; Henríquez ViNáAS (2014), pp. 125, 128, 131 y 135-136; Malarino (2010), pp. 437-441; Mejía (2014), pp. 118 y 138-144; Sagúés (2014a), p. 16, especialmente en nota 4; PAÚl (2013), nota 4 (p. 304) y pp. 313-314. 
siguiente- se vinculan en mayor o menor medida con esta violación del principio de legalidad, aunque como se ha mencionado, en general no se distingan de este primer inconveniente ${ }^{39}$.

Siguiendo con el análisis del presente apartado, un segundo problema ocasionado por el surgimiento del control de convencionalidad interno, es que para su aplicación se estaría obligando a los jueces domésticos a tomar en cuenta para sus fallos un material normativo foráneo, por mucho que buena parte del mismo pueda haberse incorporado al orden interno. Es decir, aun cuando se señale que los tratados internacionales suscritos por el Estado formarían parte del "bloque de constitucionalidad" 40 , debe recordarse que dentro de este "material normativo controlante" 41 debería ser considerada también la jurisprudencia de la Corte, de acuerdo a lo exigido por ella misma desde un comienzo. Esto sin perjuicio que para cierta doctrina y una escasa jurisprudencia la res interpretata producida por dicho tribunal tendría efectos erga omnes ${ }^{42}$, y que, para algunos, también debieran incluirse otros documentos internacionales (tratados, opiniones consultivas, resoluciones de varios organismos y tribunales internacionales, declaraciones, recomendaciones, etc. $)^{43}$. Mas lo claro respecto de dicha jurisprudencia $-y$ eventualmente, esos otros documentos internacionales-, es que se trata de un material jurídico nuevo, pues debe recordarse que no existe texto expreso en la Convención Americana que exija su obligatoriedad ${ }^{44}$ ni, que nosotros sepamos, en las Constituciones nacionales ${ }^{45}$. Esto sin perjuicio que resulta al menos curioso

39 En parte alude a esto BINDER (2010), pp. 173 y 175-176.

40 Gómez Robledo (2009), p. 140; Caballero Ochoa (2011), pp. 115-123, 126 y 132-133; Dulitzky (2015), pp. 56 y 65-68; Fernández GonZÁlez (2010), pp. 440- 441; Nogueira (2012b), pp. 1183-1184 y 1205-1207; Ferrer Mac-Gregor (2010), pp. 169-172; Hitters (2009), p. 117; Núñez Poblete (2012), pp. 3-4.

41 Nogueira (2012b), pp. 1181-1182; Sagüés (2010), pp. 125-127; Sagüés (s/f a), pp. 458-461.

42 Véase nota 15.

43 García Ramírez (2011), pp. 134-138; Ferrer Mac-Gregor (2011), pp. 391-394; Hitters (2008), pp. 137-141 y 148-150; Sagưés (2003), p. 216; Rey Cantor y Rey Amaya (2014), p. 240; Nogueira (2012a), p. 152.

44 Bianchi (2010), pp. 4-5; Binder (2010), pp. 161 y 173-176; Castilla (2013), p. 95; Dulitzky (2015), pp. 74-75; Henríquez Viñas (2014), pp. 128, 131, $135-136$ y 138; Malarino (2010), pp. 437-439; Mejía (2014), pp. 118 y 138-139; Paúl (2013), pp. 113-114; Pereyra (2011), pp. 166-168.

45 Si bien se discuten los alcances de la última reforma del art. $1^{\circ}$ de la Constitución mexicana y el dictamen de su Corte Suprema en el Expediente Varios 912/2010, en relación a su art. 133, lo cierto es que el texto constitucional sólo habla de tratados, no de la jurisprudencia de la Corte Interamericana. Abordan esta cuestión 
que en varios países en que ni siquiera la jurisprudencia emanada de sus propios tribunales resulta obligatoria, la internacional tenga este carácter ${ }^{46}$.

Un tercer problema que detectamos es que estos "jueces interamericanos" serían los primeros encargados de determinar una posible responsabilidad internacional del Estado, si bien en un sentido negativo, si así pudiera decirse. Ello, porque dichos órganos jurisdiccionales no la declaran expresamente, pero al aplicar el control de convencionalidad -sobre todo cuando su uso implica dejar de lado la normativa doméstica-, en el fondo estarían evitando que ella surja, con lo cual, a fin de cuentas, han tenido que identificarla al menos como una mera posibilidad. Mas, la declaración de responsabilidad internacional del Estado es una función propia de los tribunales supranacionales, no de los nacionales, con lo cual nuevamente estarían cumpliendo una labor para la que no han sido investidos ${ }^{47}$.

Por último, un cuarto problema es que la relación entre los jueces de distinta jerarquía dentro de cada Poder Judicial podría verse seriamente afectada en virtud de la aplicación del control de convencionalidad interno, no sólo porque serían posibles diferentes posturas al interior del mismo en sus variados niveles, sino también porque según se verá más adelante ${ }^{48}$, en último término, sería sólo la Corte Interamericana quien tendría la última palabra en cuanto a si dicho control ha sido bien o mal ejercido, sin perjuicio de que a pesar de todo lo dicho, la Corte no se considere a sí misma una "cuarta instancia" 49 . Con todo, ello puede alterar profundamente las relaciones entre los jueces de distinto nivel al interior de cada país, lo que podría

con diferentes criterios, entre otros, CAStilla (2011a), pp. 123-157; CARbonell (s/f), pp. 76-80; Ferrer Mac-Gregor (2011), pp. 340-345, 361-368 y 400-421; García Ramírez (2011), pp. 154-159; Orozco (2011), pp. 85-98. Igualmente, se comentan fallos de tribunales superiores de diversos países latinoamericanos que aceptan la obligatoriedad de esta jurisprudencia (entre otros, Ferrer MAC-Gregor (2011), pp. 356357; BAZÁN (2012), pp. 37-46; NogUeira (2012b), pp. 1176-1179, 1189-1194 y 1204-1217), aunque es importante tener en cuenta lo señalado por la Procuraduría General de la Nación argentina en su Dictamen del 10-03-2010. Expediente 93/2009, letra A (BiAnChi (2010), pp. 4-5; PereYra (2011), pp. 166-169). Lo importante, a nuestro juicio, es que hasta ahora, que sepamos, no existe ninguna modificación de un texto constitucional propiamente dicho que incorpore como material normativo controlante a esta jurisprudencia. Sin referirse a este caso, son de la misma opinión Malarino (2010), pp. 440-441 y 450-452; HenríqueZ VIÑAS (2014), p. 128.

46 Desde una perspectiva algo diferente, DuliTZKY (2014), pp. 553-556.

47 Castilla (2011b), pp. 606-610; Castilla (2013), pp. 76-77 y 83-85; Castilla (2014), pp. 168-169. En un sentido parecido, Malarino (2011), pp. 53-54.

48 Véase infra epígrafe 7.

49 Ferrer Mac-Gregor, Voto Razonado en Corte IDH, Caso Cabrera García y Montiel Flores vs. México (2010), párr. 10 y 11; HitTers (2008), pp. 135-136; HitTers (2009), p. 112. 
incidir también en el empleo y efectos de los recursos procesales correspondientes. Sobre esto se volverá a propósito del "diálogo interjurisdiccional" 50.

\section{EL MODO DE APLICAR ESTE CONTROL}

\section{DE CONVENCIONALIDAD INTERNO EN SU VERSIÓN FUERTE}

En este epígrafe se analizarán algunos de los problemas que, a nuestro juicio, surgen de cara a la actividad de los jueces locales como consecuencia de aplicar el control de convencionalidad fuerte, quedando para el siguiente la exposición de lo que origina la versión débil del mismo.

La Corte ha señalado reiteradamente que este control de convencionalidad deben hacerlo todos los jueces locales aun si no pertenecen al Poder Judicial ${ }^{51}$ (con lo que este deber se extendería a los tribunales constitucionales) y, además, ex officio. Pero también señala que deben hacerlo "evidentemente en el marco de sus respectivas competencias y de las regulaciones procesales correspondientes" 52 . Es decir, para aplicarlo, están obligados a seguir los cauces que existan en cada país para ejercer su propio control de constitucionalidad.

Sin embargo, aquí se presenta otro problema, puesto que, como comenta la doctrina, existen diferentes sistemas de control de constitucionalidad, lo que podría dar origen a una situación en la cual las atribuciones que la Corte pretende otorgar e incluso exigir a los jueces locales para ejercer el control de convencionalidad, sean mayores que las propias del control de constitucionalidad, a cuyos cauces formales, según se ha dicho, exige remitirse ${ }^{53}$.

Para comprender lo anterior y de cara al objetivo de este trabajo, es necesario tomar en cuenta cuatro características que puede tener el control de constitucionalidad, agrupadas en dos binomios. Las dos primeras características (o el primer binomio) se refieren a la existencia de sistemas de control de constitucionalidad concentrados y difusos ${ }^{54}$. Como se sabe, los primeros sólo otorgan a algunos jueces

\footnotetext{
50 Véase nota 97.

51 Incluso algunos agregan al Ministerio Público y a la Defensoría Penal Pública (GARCía Pino (2014), p. 370).

52 Desde Caso Trabajadores Cesados del Congreso vs. Perú (2006) en adelante. Véase nota 9.

53 DulitzKy (2014), pp. 541-542; Dulitzky (2015), pp. 60-64; CASTilla (2013), pp. 76-77 y 85-86; García Pino (2014), pp. 369-370; Casal (s/f), título 2b.

54 Binder (2010), pp. 173-174; Contesse (2013), pp. 6-7; García Pino (2014), pp. 368-370; Henríquez Viñas (2014), pp. 119 y 123-125; CASAl (s/f), título 2a; NogueIra (2013c), pp. 262-264; Con todo, para algunos el control de convencionalidad no es asimilable al de constitucionalidad (CASTILLA (2013), pp. 68-75).
} 
(tribunales constitucionales y/o cortes supremas) la competencia para declarar la inconstitucionalidad de la norma impugnada y, los segundos, permiten que todos los jueces puedan hacerlo. Las dos últimas características (o el segundo binomio) del control de constitucionalidad consisten en que éste puede ser a petición de parte o de oficio 55 .

Por tanto, si se toman en cuenta estas cuatro características, se percibe claramente que la Corte Interamericana está exigiendo un control de convencionalidad difuso y de oficio.

Sin embargo, el problema se presenta porque al mismo tiempo de establecer su tipo de control de convencionalidad ideal, ella señala que éste debe hacerse "evidentemente en el marco de sus respectivas competencias y de las regulaciones procesales correspondientes". Así pues, y según se ha dicho, es perfectamente posible que en varios países el control de constitucionalidad preexistente no tenga estas características.

En efecto, si se combinan los cuatro elementos antes señalados, hipotéticamente podrían tenerse también cuatro sistemas diferentes de control de constitucionalidad, que se ordenan desde la posibilidad más restrictiva hasta la más amplia: a) concentrado y a petición de parte; $b$ ) concentrado y de oficio; $c$ ) difuso y a petición de parte, y d) difuso y de oficio ${ }^{56}$.

Ahora bien, si de acuerdo a la Corte es necesario ceñirse por razones "evidentes" al "marco de sus respectivas competencias y de las regulaciones procesales correspondientes", la única forma en que un juez local podría ejercer el control de convencionalidad ideal, sería que en su país existiese un control de constitucionalidad difuso y de oficio. En todos los demás casos, la regulación interna impediría un ejercicio pleno del mismo, amordazándolo. Así: a) en un sistema concentrado y a petición de parte, sólo podrían hacerlo algunos jueces (los tribunales de más alta jerarquía), a condición que sea solicitado por quien corresponda; b) en un sistema concentrado y de oficio, únicamente podría y debería ser ejercido por los tribunales autorizados para ello, nuevamente los superiores de un país, y c) finalmente, en un sistema difuso y a petición de parte, cualquier tribunal sería competente para llevar a cabo dicho control, pero sólo si se solicita por quienes

55 Dulitzky (2014), pp. 541-542; BAZÁn (2012), nota 36 (p. 36); CASTILla (2014), p. 166; Henríquez Viñas (2014), p. 132 y de forma más implícita en p. 138; Mora Méndez (2012), pp. 218-219.

56 Sin embargo, para algunos el carácter "difuso" y su naturaleza "ex officio" serían indivisibles (FERRER Mac-Gregor, Voto Razonado en Corte IDH, Caso Cabrera García y Montiel Flores vs. México (2010), párr. 42). 
estén autorizados a hacerlo. Por tanto, en estos tres últimos casos no se estaría actuando como la Corte pretende.

Todo lo dicho nos lleva a concluir que parece algo contradictorio que la Corte señale que es obligatorio realizar un control de convencionalidad -al menos el fuerte- por todos los jueces de un Estado ex officio y, al mismo tiempo, exija que dicho control deba someterse a las respectivas competencias y regulaciones procesales correspondientes, porque entre ambas puede existir una clara incompatibilidad ${ }^{57}$.

Con todo, parte de la solución a este asunto podría radicar en la posibilidad que los jueces incompetentes para realizar el control de constitucionalidad (y, por tanto, el de convencionalidad) eleven los antecedentes a los magistrados habilitados de su país para que lo efectúen en su lugar ${ }^{58}$.

Sin embargo, el problema es que la Corte señala reiteradamente que en caso de no realizarse este control del modo que ella pretende, el país caería en responsabilidad internacional. Mas dicho Estado podría razonablemente alegar, en caso de ser demandado ante dicho tribunal, que no ha podido ejercer este control del modo en que la Corte lo exige, precisamente, porque también ha ordenado remitirse a las competencias y normas procesales correspondientes de dicho país ${ }^{59}$; y como se sabe, las autoridades sólo pueden actuar dentro de la esfera de sus atribuciones, previamente establecidas por la Constitución y las leyes.

En parte este problema ha sido abordado por el juez Ferrer Mac-Gregor en su voto disidente del Caso Likiat $^{60}$, si bien es un tema que por razones de espacio no podemos desarrollar aquí. De acuerdo a lo señalado por el jurista mexicano, amparándose en el art. 25 de la Convención Americana, que establece el "derecho al recurso", los países sometidos a la misma debieran contar con herramientas procesales idóneas para la plena protección de los derechos humanos, lo cual obligaría, en el fondo, a modificar las competencias y regulaciones procesales correspondientes a fin de lograr, como pretende la Corte, un control de convencionalidad difuso y ex officio.

No obstante el anterior razonamiento estaría confirmando que la Corte no puede dar órdenes ni atribuir competencias de manera directa a los organismos

57 Castilla (2011b), p. 612; Contesse (2013), p. 8; Dulitzky (2014), p. 541.

58 Casal (s/f), título 2a; Nogueira (2012c), p. 102; Sagứs (2009), p. 2; Ferrer Mac-Gregor, Voto Razonado en Corte IDH, Caso Cabrera García y Montiel Flores vs. México (2010), párr. 39.

59 Castillla (2011b), p. 603; Castilla (2013), pp. 75-79 y 85-86.

60 Ferrer Mac-Gregor, Voto Concurrente en Corte IDH, Caso Liakat Ali Alibux vs. Suriname (2014), párr. 91-92, 102, 110, 117-118 y 124. Ideas en parte similares en SAGỨés (s/f b), pp. 388-389. 
locales, requiriéndose siempre una autorización legal interna para ello, según se ha mencionado en el epígrafe anterior ${ }^{61}$. Lo que sí puede hacer es invitar a cada país a modificar sus ordenamientos jurídicos en tal sentido, mediante recomendaciones o a través de la declaración de responsabilidad internacional por no contar con este mecanismo en caso que dicha situación llegue a su conocimiento para ser juzgada ${ }^{62}$. Pero se insiste, debe ser el propio país quien tome la iniciativa y realice las modificaciones legales y/o constitucionales correspondientes.

En síntesis y resumiendo: la idea de la Corte es que los jueces locales sean "jueces interamericanos" y que apliquen, todos, el control de convencionalidad fuerte de oficio, lo cual podría verse más o menos mermado de acuerdo a las competencias y atribuciones procesales que existan en cada Estado para realizar el control de constitucionalidad, sin perjuicio de que el propio país pueda hacer modificaciones a dicho orden interno a fin de amoldarlo a lo que la Corte solicita, en virtud del art. 2 de la Convención Americana.

Sin embargo, buena parte de lo dicho hasta aquí podría superarse, según se ha señalado, en atención a que el control de convencionalidad interno posee dos manifestaciones (la fuerte y la débil), situación que pasa a desarrollarse a continuación ${ }^{63}$.

\section{El CONTROL DE CONVENCIONALIDAD DÉBIL Y EL ESTÁNDAR mínimo del Derecho Internacional de los Derechos Humanos}

Tal como se mencionaba más arriba, el control de convencionalidad interno posee dos facetas distintas, las que también han sido llamadas "destructiva" y "constructiva"64. La primera correspondería a la facultad que tendría el juez local, de acuerdo a lo señalado por la Corte, de "inaplicar" la norma inconvencional (sea lo que fuere que signifique esto, tema que no tratamos aquí), cuando ella resulta manifiestamente contraria a la Convención Americana, así como a la

61 Desde varias perspectivas distintas, CONTESSE (2013), nota 23 (p. 11) y p. 13; BINDER (2010), pp. 173-176; Henríquez Viñas (2014), p. 125; Dulitzky (2015), pp. 58-59; Malarino (2010), pp. 437-438; Malarino (2011), pp. 60-61; Castilla (2013), nota 25 (p. 62) y p. 74; Castilla (2014), p. 162; Mejía (2014), p. 144.

62 Una idea similar en Castilla (2013), p. 74.

63 Ferrer Mac-Gregor, Voto Razonado en Corte IDH, Caso Cabrera García y Montiel Flores vs. México (2010), párr. 35; Ferrer Mac-Gregor (2011), pp. 389-390.

64 SAgUUés (2012b), pp. 26-27; SAGÜés (s/f a), p. 464; SAgÜés (2014a), p. 190; SAgÜés (2014b), pp. $222-$ 223; SAGÜÉs (s/f b), pp. 385, 387-388, 391-394 y 397. 
jurisprudencia elaborada a partir de la misma ${ }^{65}$. Esta es la faceta que más ha llamado la atención y creado la mayor polémica y a la cual aluden los problemas mencionados en el apartado anterior. La segunda posibilidad apuntaría a una armonización entre la normativa local y las disposiciones internacionales, en el sentido de interpretar la primera a la luz de las segundas, lo que es llamado también "interpretación conforme"66. De esta manera, se salvaría la vigencia de la norma doméstica y el "daño" al ordenamiento local sería menor, aunque se ha dicho también que "es mucho más sencillo invalidar un precepto antes que reciclarlo"67.

En consecuencia, el control de convencionalidad interno podría ser cumplido mediante esta interpretación conforme entre la norma local y la disposición internacional, evitando así que el Estado caiga en responsabilidad internacional.

Con todo, igualmente en este caso debieran seguirse, por expreso mandato de la Corte, las respectivas competencias y regulaciones procesales correspondientes.

Ahora bien, y aun cuando el "daño" al orden jurídico local sea menor, a nuestro juicio, nuevamente se asiste a un otorgamiento directo de competencias a los jueces locales por parte de la Corte Interamericana, lo cual contradice abiertamente el principio de legalidad y, por tanto, estas competencias y regulaciones procesales correspondientes.

En efecto, la obligación de realizar esta armonización en virtud del control de convencionalidad interno está imponiendo, y en el fondo exigiendo, una manera diferente de interpretar la normativa local, la cual puede apartarse notoriamente de las normas internas que regulan la determinación de su sentido y alcance.

En realidad, esta situación es casi segura, dado que el Derecho Internacional de los Derechos Humanos posee sus propias reglas de interpretación, muy distintas a las que suelen existir en un ordenamiento jurídico local, al ser considerados los tratados internacionales como "instrumentos vivos" 68 .

65 Rey Cantor (2008), pp. 261-262; Ferrer Mac-Gregor (2011), pp. 343-344 y 386-390; García Pino (2014), pp. 356 y 359-360; García Pino y Contreras (2014), pp. 217-218; Nogueira (2012b), pp. 11861187; Nogueira (2013b), pp. 546-547; Ferrer Mac-Gregor, Voto Razonado en Corte IDH, Caso Gelman vs. Uruguay. Supervisión de cumplimiento de sentencia (2013), párr. 12, 84 y 85.

66 Véase nota 10.

67 SAGỨés (2014c), p. 18.

68 Vásquez; Serrano (2011), p. 145; Galdámez (2007), pp. 343-344; CanÇAdo (2006), pp. 47-48; NúNez Poblete (2011), pp. 53-54. 
De esta manera, y sólo se menciona a modo ilustrativo, suele decirse que la interpretación de los tratados de derechos humanos es evolutiva ${ }^{69}$, sistemática ${ }^{70}$ y finalista ${ }^{71}$, lo que obliga a tener una visión holística de los mismos ${ }^{72}$; o que estos derechos son interdependientes ${ }^{73}$ e indivisibles ${ }^{74}$, y tienen además un sentido autónomo $^{75}$. Lo anterior, sin perjuicio de la interdependencia entre los propios tratados de derechos humanos ${ }^{76}$.

Pero, además, debe recordarse que para esta interpretación deben utilizarse, entre otros, el principio pro homine $e^{77}$, el de progresividad o de no retroceso ${ }^{78} \mathrm{y}$ el de proporcionalidad ${ }^{79}$.

Con todo, y pese a ser tan diferentes a las herramientas nacionales, algunos autores han llamado a los jueces locales a empaparse de estas reglas y principios internacionales ${ }^{80}$ :

"El juez nacional debe aplicar no sólo el corpus iuris interamericano y la jurisprudencia de la CIDH, sino también los métodos de interpretación desarrollados por la CIDH: la interpretación evolutiva, dinámica y finalista; el uso de principios básicos de interpretación de derechos: 'pro homine' o 'favor persona', progresividad, proporcionalidad, para sólo señalar algunos de ellos, los que constituyen una fuente de ampliación de su potestad jurisdiccional..." 81 .

69 CançAdo (2006), pp. 23-25, 40, $46-49$ y 530-531; Agullar (2009), pp. 92-93; Galdámez (2007), pp. 442-486; Vásquez; Serrano (2011), pp. 159-164; Ferrer Mac-Gregor y Pelayo (2012), pp. 149-150.

70 Vásquez; Serrano (2011), pp. 151-155; Orozco (2011), pp. $85-98$ p. 93; Albanese (s/f), p. 7.

71 Amaya (2005), pp. 344-345; Aguilar (2009), p. 125; Núñez Poblete (2011), p. 54; Cançado (2006), pp. 27, 40 y $168-169$.

72 Vásquez; Serrano (2011), p. 155; CanÇAdo (2006), pp. 155, 164 y 166-167.

73 Vásquez y Serrano (2011), pp. 151-155; Albanese (s/f), p. 7; Castilla (2011a), pp. 154-157.

74 Cançado (2006), pp. 65-72 y 93-144; Ferrer Mac-Gregor (2011), p. 366; VÁsquez y Serrano (2011), pp. 148-159; OROZCO (2011), pp. 93-94.

75 Meier (2011), p. 334; Núñez Poblete (2011), p. 53; Cançado (2006), pp. 26-30 y 52.

76 Vásquez y Serrano (2011), pp. 151-155; Albanese (s/f), p. 7; Castilla (2011a), pp. 154-157.

77 Amaya (2005), pp. 337-380; Nogueira (2012a), pp. 153-154 y 158-161; Ferrer Mac-Gregor (2011), pp. 340-358, 361-366 y 387-390; Gómez Robledo (2009), pp. 141-142; Díaz Tolosa (2012), pp. 334-335.

78 Ayala Corao (2012), pp. 655 y 665-678; Juliano (2009); Nogueira (2012c), pp. 69, 82 y 88; Nogueira (2009), p. 423.

79 Contreras (2014), pp. 236-250; Barbosa (2012), pp. 54-59; Benavides (2009), p. 303; Londoño (2010), pp. 774-775 y 795; Malarino (2011), pp. 51-53.

80 Nogueira (2012c), pp. 82 y 88; Nogueira (2013b), pp. 521 y 532; Nogueira (2013c), p. 234.

81 Nogueira (2012c), p. 82. 
O como agrega este autor en otro sitio,

“...todo lo que constituye una fuente de ampliación de su poder creador de derecho"82.

Pero esto no es todo: la exigencia de interpretar el derecho local a la luz del internacional debiera ser aplicada no sólo siempre, sino que para cierta doctrina, también de manera previa a cualquier otra forma de intentar desentrañar el sentido y alcance de la normativa local por parte del juez (y de todas las autoridades nacionales ${ }^{83}$, si bien esto no se analiza aquí). Es por todo lo dicho que se ha señalado que el juez doméstico debe hacer

"relecturas adaptativas del derecho nacional, de tipo armonizante, en consonancia, esto es, 'conforme', con el Pacto y tal jurisprudencia. [...] En rigor de verdad, el juez local tendría que comenzar su análisis de la norma nacional a partir del Pacto de San José y de la aludida jurisprudencia, antes que iniciar el entendimiento de ella con los insumos jurídicos nacionales ( $v$ gr., antecedentes y propósitos de la cláusula bajo examen). Esto se explica por el realmente muy importante proceso de adaptación y de conformación de la regla interna con los parámetros externos ya señalados, que deben iluminar y guiar la comprensión y la efectivización de las normas locales" 84 .

Sin embargo, debe advertirse que lo anterior

"implica pensar, interpretar y hacer funcionar a todo el derecho interno, de conformidad con las pautas del Pacto de San José de Costa Rica, y la jurisprudencia de la Corte Interamericana de Derechos Humanos" ${ }^{\prime 5}$.

De ahí que si bien "La mutación deja incólume el texto, pero altera el contenido del mensaje normativo" 86 , el control de convencionalidad produciría -de manera algo opuesta a lo señalado por el autor precedente- el "recorte de las competencias judiciales nacionales para interpretar al derecho local”" ${ }^{2}$, razón por

\footnotetext{
82 Nogueira (2013c), p. 234.

83 Véanse notas 7 y 8.

84 SAGÜÉS (s/f b), p. 385. Para estas ideas, pp. 385-386.

85 SAGÜÉS (2014c), p. 17.

86 SAGÜÉs (2014c), nota 6 (p. 18). Si bien se refiere a una situación diferente, podría aplicarse esta reflexión suya al presente caso: "Merced del proceso de desconstitucionalización, el texto constitucional permanece incólume, pero su contenido es total o parcialmente vaciado, y algunas veces sustituido por otro. Es una tarea de desmontaje o de anestesia de la Constitución, que termina siendo solamente una suerte de fachada constitucional" (SAGÜÉS (2012a), nota 2 (p. 9).
}

87 SAGỨÉS (2012c), p. 25. 
la cual "significa una seria disminución de las competencias de los operadores locales para interpretar el derecho doméstico, comenzando por el constitucional" 88 .

Se comprende fácilmente que esta exigencia no sólo viola, según se ha dicho, las reglas de interpretación locales (y, por tanto, las competencias y reglas procesales correspondientes internas exigidas por la Corte), sino que, además, puede llevar a alterar notablemente tanto la intención o espíritu de dichas normas como su tenor literal. Es decir, las leyes pueden quedar 'desnucleadas' de su contenido original, al tener que ser reinterpretadas a la luz del Derecho Internacional, a veces forzadamente, sin perjuicio del gran dinamismo que puede tener la jurisprudencia de la Corte, que como se dijo, también se considera parte del "material normativo controlante". En consecuencia, el orden jurídico local podría verse tremendamente distorsionado en virtud de este proceso; tanto como si se inaplicara una norma suya.

Es decir, las reglas de interpretación del Derecho Internacional de los Derechos Humanos pueden hacer que el tenor literal, no sólo de los tratados, sino también de las leyes nacionales, de acuerdo a esta doctrina, importen cada vez menos. Lo anterior, sin perjuicio que por este camino también iría menguando la importancia de la normativa local (entre otras cosas, y aunque no pueda ser analizado en este trabajo, dado a que el margen de apreciación es especialmente débil en el sistema interamericano ${ }^{89}$ ), lo que además podría producir una notable homogeneización de los ordenamientos nacionales sometidos a la Corte, dejando de lado o al menos aminorando fuertemente las características propias de cada país.

Ello, sin perjuicio que puesto que los jueces locales deben inspirarse en lo que señale la Corte (se ha hablado incluso de una "fe mesiánica" 90 en su jurisprudencia), podría darse el caso que se vieran en la necesidad de aplicar una interpretación muy antigua, insuficiente para la situación actual91; salvo que haciendo uso del principio pro homine, según se verá en seguida, utilicen su normativa local, al considerarla más protectora e idónea, debiendo, eso sí, probar mediante su argumentación que esta última forma de comprender el derecho se adecúa más a las circunstancias del caso.

\footnotetext{
88 SAGǗ́s (2012c), p. 25.
}

89 Contesse (2013), pp. 29-31; Dulitzky (2015), pp. 78-79; Nogueira (2012b), pp. 1171-1172, 11801181 y 1219; CONTRERAS (2014), pp. 238-250 y 265-266, quien señala que "la doctrina del margen de apreciación, tras Artavia, no parece tener buen futuro -al menos dentro del sistema interamericano-" (p. 246).

90 DulitzKy (2014), p. 553.

91 DulitZky (2014), pp. 553-556; DulitZKy (2015), pp. 77-79. 
Sin embargo, los problemas que genera la interpretación conforme exigida por el control de convencionalidad interno son más complejos. Ello, porque se ha señalado reiteradamente que el Derecho Internacional de los Derechos Humanos sólo establece el "estándar mínimo"92 en la protección de estos derechos. De ahí que nada impida que los países establezcan una normativa más protectora a su respecto, o que los restrinjan en menor medida en los casos en que sea legítimo hacerlo. En consecuencia, en virtud del principio pro homine, el juez local estaría obligado a buscar la reglamentación más beneficiosa para la protección de los afectados o aquella que perturbe en menor medida sus derechos ${ }^{93}$.

En realidad, lo anterior viene a complicar bastante las cosas, ya que también se ha señalado que el principio pro homine estaría dejando prácticamente obsoletas las reglas de jerarquía dentro de los ordenamientos jurídicos. Es decir, el criterio jerárquico cedería ante el de mayor protección, pudiendo encontrarse dicha mejor tutela tanto en la normativa nacional como la internacional ${ }^{94}$. Sin embargo, esta determinación dependerá, al menos en un primer instante para estos “jueces interamericanos”, de cuáles sean las circunstancias de cada caso, siendo imposible determinarla a priori, que sea parcialmente.

Por tanto, el principio pro homine puede traer aparejada una notable incertidumbre respecto de la normativa que se empleará -y el modo en que será interpretada una u otra, según se señalaba más arriba- al momento de resolver diferentes casos de protección a los derechos humanos, pues no existe una manera previa de saber si empleará la reglamentación nacional o la internacional, ya que resulta perfectamente posible que esta última sea eclipsada por la primera en virtud del principio pro homine. En consecuencia, es necesario insistir que el control de convencionalidad interno no siempre conlleva el triunfo de la norma foránea ni una armonización que "desnuclee" a la disposición local"5.

Con todo, debe advertirse que la última palabra la tendría siempre la Corte Interamericana, pues según se ha dicho, en caso de llegar la causa a su conocimiento

92 Ferrer Mac-Gregor (2011), pp. 343-344 y 405-407; Nogueira (2012a), pp. 184-185; Nogueira (2012c), pp. 58-59, 84-85 y 100-102; Gómez Robledo (2009), pp. 149-150; MeIER (2011), pp. 332-333 y 369-371.

93 Hitters (2013), pp. 708-709; García Ramírez (2011), pp. 133-139; Ferrer Mac-Gregor, Voto Razonado en Corte IDH, Caso Gelman vs. Uruguay. Supervisión de cumplimiento de sentencia (2013), párr. 69.

94 Nogueira (2012a), pp. 153, 160-161 y 185; Castilla (2011a), pp. 149-153; Caballero Ochoa (2011), pp. 109-112, 128 y 130; Núñez Poblete (2008), p. 359; NúŃez Poblete (2010), pp. 454-458.

95 Un interesante estudio en que se analizan varios casos en que puede primar la norma local sobre la disposición internacional puede verse en León Henríquez (2014), especialmente en pp. 67-81. 
luego de agotadas las vías internas, no basta con que el Estado demandado señale que el juez local ejerció en su momento el control de convencionalidad, pues, en teoría, el tribunal internacional siempre podría corregir su aplicación. Dicho de otra manera, más que hacer el control de convencionalidad, la Corte exige que se haga un correcto control de esta especie ${ }^{96}$. Sin embargo, en virtud del principio pro homine, no existe una manera previa de saber -ni para la Corte ni para el juez nacional-: a) si triunfará la norma internacional (en el caso del control "destructivo" o "fuerte"); b) si la disposición local se verá más o menos modificada en su interpretación -desnucleada- por la internacional (en el control "constructivo" o "débil"), o $c$ ) si esta última quedará incólume, en virtud del principio pro homine.

Ahora bien, buena parte de la doctrina alude a esta interacción entre jueces estatales e internacionales refiriéndose a la misma como un "diálogo interjurisdiccional”, estimando que ella podría contribuir al enriquecimiento mutuo y, en definitiva, a mejorar la protección de los derechos humanos en el sistema interamericano ${ }^{97}$. Sin embargo, dadas las reglas del control de convencionalidad interno y sobre todo del externo que ha establecido la Corte, parece algo forzoso hablar a este respecto de un "diálogo". Ello, puesto que aunque resulta obvio que esta última podría tomar en cuenta algunas argumentaciones de los jueces nacionales, dicho "diálogo" no se realiza en un plano de igualdad, sino de total subordinación, con lo cual el tribunal internacional siempre puede terminar imponiendo su parecer ${ }^{98}$. Esta es la razón por la que algunos han hablado de un diálogo unidireccional99.

En consecuencia, el control de convencionalidad "débil", que exige una interpretación armonizante, también presenta varias incógnitas, no sólo de competencia y de regulaciones procesales correspondientes, sino sobre todo, y gracias al principio pro homine, para saber cuál normativa se aplicará, la nacional o la internacional. Ello, en razón de carecer de mecanismos a priori y que no sean casuísticos para su determinación.

Esto es importante, pues si bien el principio pro homine ha sido invocado desde el inicio como uno de los fundamentos del control de convencionalidad,

96 Ferrer Mac-Gregor (2010), p. 22; García Pino (2014), pp. 375-376; Sagüés (s/f b), pp. 385-386; CONTESSE (2013), p. 15.

97 Nogueira (2012a), pp. 149-187; Nogueira (2013a), pp. 221-274; Ferrer Mac-Gregor (2014), p. 240; Caballero Juárez (2009), pp. 193-209; García Pino (2014), pp. 375-376.

98 Dulitzky (2015), p. 48. Refiriéndose al control de convencionalidad externo, García Pino (2014), p. 375.

99 DulitzKy (2014), pp. 554, 557 y 560; Dulitzky (2015), pp. 76-77; CONTESSE (2013), pp. 14-15 y 31. 
posee, no obstante, también aspectos que pueden ocasionar más de un cortocircuito con el mismo.

\section{6. “JUECES INTERAMERICANOS” Y DIVERSAS CLASES DE INTERPRETACIÓN}

La situación descrita puede hacerse aún más compleja, si bien algunos de los problemas que se plantearán en este epígrafe son sólo hipotéticos. En efecto, dado que el principio pro homine -y podría agregarse aquí también el principio de progresividad- obliga al juzgador a buscar la normativa más favorable, cierta doctrina ha señalado que en virtud de lo anterior, los jueces locales podrían mejorar los estándares alcanzados por la Corte no sólo aplicando la normativa local en caso de ser más favorable, sino también extendiendo la interpretación de los instrumentos internacionales ya realizada por dicho tribunal, yendo así más allá del mismo, o incluso, abriendo nuevos y originales derroteros en materias respecto de las cuales no se haya pronunciado aún ${ }^{100}$.

Es decir, como la Corte estima que sus veredictos son sólo el "estándar mínimo", se estaría invitando a los jueces locales a asumir tal vez más que nunca su papel de "jueces interamericanos", dándoles la facultad de superar a la misma Corte mediante interpretaciones más originales y creativas o también nuevas, si eventualmente ella no lo ha hecho todavía.

Con lo anterior, podría darse el caso que la propia Corte se quede "corta" en su exégesis de la normativa internacional, siendo superada por algún juez local más original u osado. Aunque igual que en los casos anteriores, el tribunal interamericano tendría siempre la última palabra, de llegar el caso a su conocimiento, pues en el fondo, y por mucha libertad e innovación que se busque conseguir con el principio pro homine, el de progresividad o el estándar mínimo, en teoría nada puede ir contra lo que éste considere correcto. Por eso se señalaba más arriba que este "diálogo interjurisdiccional" tiene sus limitaciones.

Pero las dos situaciones anteriores hacen surgir dos problemas más. El primero, porque otra vez se le están confiriendo atribuciones nuevas al juez local $-\mathrm{y}$, por tanto, saltándose las competencias y reglas procesales correspondientes-, pues de acuerdo a esta doctrina, ahora no sólo podría innovar respecto de su Derecho interno, sino también respecto de normas internacionales (y cabría, además, preguntarse sobre cuáles: tratados, jurisprudencia, opiniones consultivas, soft law, etc.), de forma que, ahora sí, estaría actuando verdaderamente como un "juez

100 Véanse notas 101,103 y 104. 
interamericano". Y el segundo -si bien es un caso hipotético-, porque dado lo anterior, no queda claro si en esta labor extensiva o innovadora, el juez puede y/o debe aplicar las reglas de interpretación nacionales o internacionales. Se podría concluir que, en virtud del principio pro homine, debiera tener la facultad de acudir a las más favorables, que por tratarse de un asunto casuístico, podrían ser unas $\mathrm{u}$ otras.

Ahora bien, volviendo a las labores que podrían o debieran realizar los jueces domésticos en su tarea exegética a la luz del control de convencionalidad, del principio pro homine, del de no retroceso y del estándar mínimo, de acuerdo a cierta doctrina, existen varias posibilidades a las cuales podrían verse enfrentados.

En efecto, el profesor Nogueira habla de seis clases de interpretación posibles por parte del juez local ${ }^{101}$, las que adhieren a la visión según la cual, la res interpretata de las sentencias de la Corte posee efectos erga omnes ${ }^{102}$. Estas son:

a) Interpretación extensiva: es aquella realizada por el juez nacional, quien tendría la posibilidad de ir más allá de lo establecido por la Corte en la protección de un derecho con su propia interpretación. Estas decisiones nacionales podrían influir luego en la Corte, aunque habrá que esperar su veredicto, mediante el cual tendría la libertad de aprobar o desaprobar dicha interpretación, siendo por ello un diálogo "potencial"103.

b) Interpretación innovadora: es aquella en que se abordan derechos no analizados antes por la Corte, cuando existe silencio de su parte o se trata de una situación "en blanco". Se crea así una solución jurisprudencial inédita, en la cual el juez local "puede liberarse de la servidumbre de la ley nacional" 104 , teniendo la facultad de otorgar mayores alcances, aminorar restricciones, dar nuevos enfoques a los derechos involucrados y también de censurar a la norma nacional. Esto genera un "diálogo ascendente, el cual queda suspendido hasta que la $\mathrm{CIDH}$ conociendo de un caso análogo confirme o revierta la decisión adoptada por el juez nacional" 105 . Ahora, lo importante para este autor es que "El juez nacional debe proceder a esta innovación, estudiando la jurisprudencia interamericana para pronosticar cuál será la solución desarrollada por el juez interamericano en

101 Nogueira (2012a), pp. 149-187; Nogueira (2012c), pp. 57-140; Nogueira (2013a), pp. 221-274; Nogueira (2013b), pp. 511-553; Nogueira (2013c), pp. 221-270.

102 Véanse nota 15.

103 Nogueira (2012c), pp. 89-90; Nogueira (2013b), pp. 531-532; Nogueira (2013c), pp. 234 y 248-249.

104 Nogueira (2012c), p. 90.

105 Nogueira (2012c), p. 90. 
contenciosos inéditos. Si el juez nacional actúa de otra manera arriesga la condenación posterior de parte de la CIDH"106.

c) Interpretación correctiva: que ocurre cuando luego de haber sido condenado por la Corte, el juez local enmienda la jurisprudencia nacional que era contraria a la de este fallo internacional y los futuros casos se inspiran en él ${ }^{107}$.

d) Interpretación neutralizadora: que es aquella que busca evadir o deja sin efecto la interpretación de la Corte, desoyéndola, con lo cual hace caso omiso del estándar mínimo establecido por este tribunal, yendo más allá de lo que podría justificarse en virtud del margen de apreciación ${ }^{108}$.

e) Interpretación receptiva: es decir, aquella en que el juez nacional se adhiere a la ratio decidendi de sentencias condenatorias a otros países, o a principios establecidos en opiniones consultivas, sin esperar a una condena a su Estado, siguiendo los estándares mínimos de la Corte. Así, evita inconvencionalidades, teniendo una función preventiva ante eventuales responsabilidades internacionales del Estado ${ }^{109}$.

f) Interpretación discordante: finalmente, es la que muestra su total desacuerdo con un fallo de la Corte, por considerarlo errado, para lo cual le corresponde argumentar su decisión. Sin embargo, igual que en otras ocasiones, la última palabra la tiene el tribunal internacional ${ }^{110}$.

Debe destacarse respecto de la interpretación innovadora-letra $b$ ) - y en menor medida en el caso de la interpretación extensiva -letra a)-, que en la eventualidad de darse una "inaplicación" de la normativa local, estaríamos ante una situación incluso más drástica que la contemplada por el control de convencionalidad fuerte o represivo, pues en estas últimas hipótesis el juez local podría en teoría inaplicar una norma doméstica no basándose en un previo fallo de la misma Corte, sino en una interpretación original -o extensiva- suya, que de alguna manera, pretende "anticipar" lo que hubiera dicho ese tribunal en su lugar. Es decir, estaríamos eventualmente en presencia de un control de convencionalidad fuerte por vía de interpretación innovadora -o extensiva- del juez nacional, lo

106 Nogueira (2013c), p. 234. Con las mismas palabras, Nogueira (2013b), 521. Para estas ideas, Nogueira (2012c), pp. 89-91, 103 y 110-121; Nogueira (2013b), pp. 521-522 y 532-533; Nogueira (2013c), pp. 234-235 y 249-250. Sin llamarla así, trata esta misma situación, SAGỨs (2014b), p. 224; SAGǗ́s (s/f b), p. 386.

107 Nogueira (2012c), pp. 91 y 103-108; Nogueira (2013b), pp. 533-534; Nogueira (2013c), pp. 250-253.

108 Nogueira (2012c), pp. 95-96; Nogueira (2013b), pp. 540-542; Nogueira (2013c), pp. 255-258.

109 Nogueira (2012c), pp. 94-95; Nogueira (2013b), pp. 534-540; Nogueira (2013c), pp. 253-255.

110 Nogueira (2012c), p. 97; Nogueira (2013b), p. 542; Nogueira (2013c), p. 258. 
cual, además de resultar incompatible con sus competencias y regulaciones procesales correspondientes, le estaría dando un poder enorme. Esto, sin perjuicio de tratarse de un control de convencionalidad interno en que ambas disposiciones en pugna, la controlante y la controlada, dependerían totalmente del criterio del mismo juzgador, con lo que, en definitiva, podría incluso estar creando Derecho Internacional (sea lo que fuere que se entienda por el mismo).

Pero además, según este autor, lo anterior sería una obligación (incluso "pronosticar" cuál podría ser la solución de la Corte), al punto que en caso negativo podría comprometer la responsabilidad internacional del Estado. Lo cual querría decir que el juez local estaría en necesidad de realizar siempre una interpretación innovadora de los instrumentos internacionales en aquellos casos en que la Corte no lo haya hecho antes (aunque nada impediría que aplicara la normativa local si la considera más favorable). Sea como fuere, no queda claro si este supuesto control de convencionalidad lo haría en virtud del criterio de la Corte o del suyo propio. Finalmente, debe advertirse que tampoco queda claro a qué se refiere exactamente el autor en este caso cuando habla de "censurar" a la norma nacional, aunque da la impresión que asimila dicho término al de "inaplicar".

Por otra parte, también conviene traer a colación lo señalado por el profesor Sagüés, quien distingue tres clases de interpretación ${ }^{111}$ :

a) Interpretación mutativa por adición (que es a la cual más alude este autor): es aquella en que "el tribunal ha agregado algo al contenido inicial formal del Pacto, aunque el texto de éste no ha variado"112, o que "suma al contenido original del mensaje normativo, un ingrediente suplementario" 113 .

b) Interpretación mutativa por sustracción: es la que "quita -por vía de interpretación- al contenido material de una norma un ingrediente anómalo, incompatible"114 con lo señalado por la Corte.

c) Finalmente, "la interpretación mutativa mixta, por sustracción-adición, por cierto más atrevida, realiza un operativo doble, con el mismo fin de salvar a una cláusula normativa de su aniquilación como inconstitucional o inconvencional:

111 SAGÜÉS (2009), pp. 3 y 6; SAGÜÉs (2010), p. 132; SAGÜÉs (2012b), p. 27; SAGÜÉS (2014a), pp. 191-192; SAGÜés (2014b), pp. 123-224; SAGỨs (2014c), pp. 16 y 18-22; SAGÜés (s/f a), pp. 458 y 467.

112 SAGÜÉS (2009), p. 3; con las mismas palabras: SAGÜÉs (s/f a), p. 458.

113 SAGǗS (2014b), p. 224.

114 SAGǗs (2014b), p. 224. 
disminuye un tramo del contenido material de una norma, y le inserta otro"115. Estas últimas también son llamadas "sustitutivas"116.

Lo importante es que, en estos casos, "la mutación el texto de la norma permanece incólume, pero su contenido material varía, sea por restricción, aumento o reemplazo" 117 .

Ahora, debe tenerse presente que aun cuando al hablar de la interpretación mutativa por adición el profesor argentino aluda sobre todo a la exégesis realizada por la Corte, y al referirse a la mutativa por sustracción, a la hecha por los tribunales locales para seguir los criterios de aquélla, ambas, así como la interpretación mixta, podrían ser utilizadas tanto por los jueces locales como por los internacionales ${ }^{118}$, todo en virtud del principio pro homine y de la idea de estándar mínimo.

Finalmente, luego de todo lo visto hasta aquí y en particular teniendo en cuenta estas diversas clases de interpretación propuestas, se puede concluir que los jueces nacionales no sólo podrían alterar profundamente el sentido de la Convención y otros documentos internacionales, así como de sus derechos nacionales, siempre que no vayan contra lo ya establecido por la Corte, sino que, de llegar a ser una realidad, se podría producir una notable incertidumbre, e incluso un auténtico caos respecto de su labor interpretativa. A este último problema se dedicará el próximo epígrafe.

\section{7. ¿ ¿SE PUEDE PONER EN ORDEN TODA ESTA CUESTIÓN?}

Luego de todo lo dicho hasta aquí, y aun reconociendo que algunas de las situaciones planteadas son -que sepamos- sólo hipotéticas, es posible distinguir al menos cinco posibilidades de acción para los jueces locales como consecuencia de la aplicación del control de convencionalidad interno, del principio pro homine, de la idea de estándar mínimo y de las diversas clases de interpretación analizadas:

a) Control de convencionalidad fuerte o represivo, en virtud del cual, la norma nacional sería "inaplicada" por el juez local en pos de la internacional, sea lo que fuere que esto signifique (y que no puede ser analizado aquí);

115 SAGÜÉs (2014b), p. 224, cursivas en el original.

116 SAGÜÉS (2014c), p. 18.

117 SAGỨés (2014b), p. 223.

118 SAGÜÉS (20104a), pp. 191-192. 
b) Control de convencionalidad débil o constructivo, esto es, una interpretación armonizante de la normativa local, aun cuando ello pueda significar de hecho su "desnucleización";

c) Primacía de la norma local, al ser preferida en virtud del principio pro homine;

d) Interpretación extensiva de la norma internacional por el juez local, yendo más allá de lo previamente establecido por la Corte, tomado como estándar mínimo, lo que podría, a su vez, dar origen a las posibilidad a) o b). Ello, pues parece poco probable que el juez local realice una interpretación extensiva o innovadora si quisiera aplicar la normativa nacional en virtud del principio pro homine visto en la letra anterior;

e) Interpretación innovadora de la norma internacional para aquellos casos no fallados anteriormente por la Corte, con las dos mismas posibilidades señaladas en la letra anterior, aun cuando se trate de un hipotético control de convencionalidad en que el material jurídico controlante y controlado dependerían sólo del criterio del juez local.

Ahora, dado lo anterior, una cosa evidente que salta a la vista, es que parece muy probable que surjan interpretaciones muy dispares o incluso antagónicas, no sólo entre los jueces de diferentes países, sino también entre los connacionales ${ }^{11}$. O también podrían existir para casos análogos, al mismo tiempo inaplicaciones, interpretaciones armonizantes o utilización del Derecho local, igualmente entre jueces del mismo o distintos países.

Lo anterior, sin perjuicio de las diferencias que podrían surgir dentro de las propias instancias de cada Poder Judicial, lo que se complica más aún, en atención, como se mencionó más arriba, a que todos los jueces locales deberían responder en último término ante la Corte Interamericana, pese a no considerarse ella como una cuarta instancia.

Es decir, todo lo dicho hasta aquí respecto de la inaplicación de la norma local, la interpretación armonizante, el triunfo de la norma nacional y sobre todo en las interpretaciones extensiva e innovadora, nos lleva a concluir que pese a sus buenas intenciones, el principio pro homine, unido al de progresividad y a la idea de "estándar mínimo", pueden dar origen a un notable desorden, contradicciones e incertezas en la sentencias de los jueces nacionales, que lejos de unificar los criterios del sistema interamericano, como ha pretendido la Corte al instaurar la doctrina del control de convencionalidad interno, podrían ocasionar un auténtico

119 DulitzKy (2014), pp. 552-553. Si bien referido al caso mexicano luego de su última reforma constitucional, alude a este problema Del Castillo (s/f), título I. 
caos interpretativo, por mucho "diálogo jurisdiccional" que pudiera existir entre tribunales del mismo país, de diferentes Estados, o -con las salvedades anotadas en su momento- entre éstos y la propia Corte.

Ahora bien, según se ha dicho, es la Corte Interamericana quien tendría la última palabra en todos los casos en que los jueces nacionales, actuando como "jueces interamericanos", apliquen el control de convencionalidad fuerte, débil, prefieran su normativa local o -hipotéticamente- realicen una interpretación extensiva o innovadora. Ello, al corresponderle la revisión final e inapelable de la aplicación de la Convención, como intérprete última de la misma. Es por eso, como se señalaba más arriba, que no basta con que el juez local alegue haber ejercido el control de convencionalidad interno, ya que la Corte no queda inhabilitada para aplicar su propio control de convencionalidad ${ }^{120}$.

Sin embargo, parece difícil que la Corte tenga la capacidad para fiscalizar efectivamente los miles y miles de fallos de los juzgadores locales que se producirían en las diferentes hipótesis que aquí se han planteado ${ }^{121}$.

En efecto, lo anterior se debe no sólo al limitado número de sentencias que este tribunal dicta anualmente (lo cual en parte resulta explicable al no sesionar permanentemente), sino también, en razón de los plazos y demás condiciones que la propia Convención establece para interponer un reclamo internacional luego del agotamiento de las vías internas. De esta manera, puesto que se exige un lapso de seis meses desde su agotamiento, en muchísimos casos esto podría hacer impracticable dicho recurso ${ }^{122}$.

Resulta así imposible que la Corte pueda supervigilar a todo un continente, por mucho que se considere a sí misma algo así como un tribunal constitucional continental ${ }^{123}$ o pretenda instaurar un sistema obligatorio de precedentes. Además -y esto es fundamental-, a nuestro juicio, esta imposibilidad fáctica se proyecta sobre todos los demás problemas analizados en este trabajo, agudizándolos en no poca medida, razón por la cual, la implementación del control de convencio-

\footnotetext{
120 Véase nota 96.

121 DulitZKy (2014), pp. 552-553; Dulitzky (2015), pp. 48, 70-73 y 76.

122 DulitzKy (2014), pp. 553 y 557.

123 De Figueiredo Caldas, Voto Razonado en Corte IDH, Caso Gomes Lundy Otros ("Guerrilha do Araguaia") vs. Brasil (2010), párr. 5: "Para todos los Estados del continente americano que libremente la adoptaron, la Convención equivale a una Constitución supranacional referente a Derechos Humanos. Todos los poderes públicos y esferas nacionales, así como las respectivas legislaciones federales, estatales y municipales de todos los Estados adherentes están obligados a respetarla y a ella adecuarse".
} 
nalidad interno, tal como pretende la Corte y la doctrina dominante, dadas las dificultades vistas, podría hacerse relativamente ilusoria en nuestra región.

Es por eso que se decía que pese a sus afanes unificadores y homogeneizantes, la aplicación del control de convencionalidad, junto al principio pro homine, de progresividad y el criterio del estándar mínimo, podrían llevar al sistema interamericano a un auténtico caos interpretativo, y lo que es peor, a un desmedro en la protección de los derechos humanos.

\section{RESUMEN FINAL}

En atención a los varios problemas que se han abordado en este estudio -un total de catorce- y antes de arribar a las conclusiones del mismo, se ha creído oportuno rememorarlos en el orden expuesto, a fin de tener una visión orgánica de los mismos.

De esta manera, los problemas a los que se ha hecho referencia son los siguientes:

a) La nueva función que estaría dando la Corte Interamericana a los jueces nacionales, saltándose el principio de legalidad tanto a nivel nacional como internacional, al haber instaurado jurisprudencialmente el control de convencionalidad interno, al margen de si se lo aplica en su versión fuerte o débil. Este problema se ramifica en varios de los restantes inconvenientes analizados;

b) El nuevo material normativo controlante que estarían obligados a aplicar los jueces domésticos que vaya más allá de las normas internacionales efectivamente incorporadas al ordenamiento interno, ya se trate de la jurisprudencia de la Corte (como señala ella misma desde un comienzo) o de las demás y variadas disposiciones internacionales (principios, declaraciones, soft law, etc.);

c) La incompetencia que tienen los jueces nacionales para declarar la responsabilidad internacional del Estado, aun cuando en su caso busquen evitarla, mediante el uso del control de convencionalidad;

d) Los conflictos de criterios que podrían surgir entre los diferentes niveles del poder judicial de cada país, sin perjuicio del control final que eventualmente podría realizar la Corte Interamericana;

e) Las incompatibilidades que emergen del hecho que la Corte exija que el control de convencionalidad fuerte sea realizado ex officio por todos los jueces locales y, al mismo tiempo, que deba hacerse evidentemente de acuerdo a las competencias y regulaciones procesales correspondientes (y lo mismo puede decirse respecto del control débil, a la luz de los problemas siguientes);

f) Las nuevas reglas y principios de interpretación, tomados del Derecho Internacional de los Derechos Humanos, que se pretende utilicen los jueces locales 
-incluso de manera previa- en su labor de armonización entre las disposiciones internacionales y la normativa nacional (control de convencionalidad débil), sin perjuicio de no estar autorizados para ello por el orden local y de su muy diferente naturaleza respecto de las reglas de interpretación internas;

g) La "desnucleización" que puede sufrir el Derecho local con motivo de lo anterior, lo que podría llegar a tener casi los mismos efectos que su inaplicación;

h) La total incertidumbre respecto del resultado al cual podría llegar el juez local (inaplicación, interpretación armonizante o triunfo de la normativa interna) en virtud del principio pro homine, del de progresividad y de considerar al Derecho Internacional como el estándar mínimo en la protección de los derechos humanos;

i) La falta de competencia del juez local y la notable incerteza que generaría, de llegar a realizarse, una interpretación extensiva de las disposiciones internacionales, lo cual, además, podría dar origen ya sea a la inaplicación de la norma doméstica o a una interpretación armonizante a su respecto;

j) La también incompetencia del juez nacional y los aún mayores problemas que surgirían de la interpretación innovadora (la que igualmente podría dar origen a las dos posibilidades vistas en la letra anterior), sin perjuicio de que en este eventual control de convencionalidad interno, la determinación de la disposición controlante y de la norma controlada dependerían del mismo juzgador;

k) La imposibilidad de determinar a priori cuáles reglas de interpretación y qué solución podrían aplicarse en todos los casos anteriores, por depender de un análisis casuístico, motivado sobre todo por el principio pro homine, teniendo en cuenta, además, que dicho principio estaría dejando obsoletas las reglas de jerarquía entre las normas jurídicas nacionales y las disposiciones internacionales en pugna;

l) El auténtico caos que ocasionaría todo lo dicho, fruto de las múltiples e imprevisibles interpretaciones a las cuales podrían llegar tanto los jueces de un mismo país como de países diferentes;

m) La imposibilidad fáctica para que la Corte Interamericana tenga la última palabra a este respecto y supervigilar a todo un continente, lo que, a nuestro juicio, agrava sobremanera todos los demás problemas reseñados, y

n) La dispersión de enfoques y una eventual fragmentación que podría originarse dentro del sistema interamericano, pese a haberse pretendido exactamente lo contrario mediante la instauración del control de convencionalidad, en relación al principio pro homine, al principio de progresividad y a la idea del estándar mínimo.

Finalmente, y luego de haber realizado esta visión resumida y panorámica de los problemas abordados en este trabajo, es el momento de arribar a algunas conclusiones. 


\section{CONCLUSIONES}

Como puede apreciarse luego de todo lo visto hasta aquí, los problemas que origina la aplicación "fuerte" o "débil" del control de convencionalidad interno son muchos y complejos, al punto que su implementación podría hacerse basatante teórica en el continente.

De hecho, un elemento común a la mayoría de los inconvenientes detectados ( $\mathrm{y}$ otros que pudiera haber), es que en cualquier tipo de control de convencionalidad que se realice, los jueces internos están violando sus competencias y reglas procesales correspondientes. Sin embargo, estas reglas inspiradas en el control de constitucionalidad $-\mathrm{y}$ que, a nuestro juicio, no puede imponer la Corte directamente a los órganos de un Estado-, son exigidas permanentemente por este tribunal y por la doctrina dominante para su implementación.

Además, el modus operandi planteado por la jurisprudencia, y sobre todo por la doctrina, genera una total incertidumbre respecto de la solución a la que podría llegar el juez doméstico, en particular gracias al uso del principio pro homine, del de progresividad y de la idea de estándar mínimo del Derecho Internacional en la protección de los derechos humanos. Ello, pues no se sabe a ciencia cierta a qué fuentes internacionales acudirá; en virtud de qué reglas interpretará las normas nacionales ( $\mathrm{y}$, eventualmente, las internacionales); y como fruto de todo lo anterior, si dejará sin efecto la norma interna, si hará una interpretación armonizante de la misma o si la aplicará sin más.

Todo esto se agrava, por añadidura, gracias al debilitamiento del criterio de jerarquía de las disposiciones jurídicas en pugna, en virtud del principio pro homine. Es por eso que se advertía que a pesar de haber sido invocado dicho principio para fundamentar la doctrina del control de convencionalidad, podría al mismo tiempo generar varios cortocircuitos con ella.

Por otro lado, a nuestro juicio, los problemas detectados no obedecen a un vicio atribuible a los ordenamientos jurídicos nacionales, sino a un planteamiento defectuoso del control de convencionalidad. Lo anterior podría deberse a que esta doctrina ha sido desarrollada sobre todo desde una mirada internacionalista, que no se ha preocupado lo suficiente por analizar los efectos reales que su aplicación tendría en los ordenamientos locales no sólo de manera concreta, sino también desde una perspectiva global.

De hecho, de ser llevado este control a la práctica tal como pretende la Corte y la mayor parte de la doctrina, podrían originarse graves problemas tanto para la labor de los jueces locales como para su propia implementación, según se ha intentado demostrar. Lo cual, lejos de lograr, como es su intención, una unidad 
de criterios, podría dar origen exactamente a lo contrario, generando un auténtico caos interpretativo y una fragmentación dentro del sistema interamericano. Y esta situación se agrava más aún, dada la absoluta imposibilidad fáctica para que la Corte pueda supervigilar a todo un continente.

Es por eso que creemos que hace falta una visión más orgánica del control de convencionalidad, que aborde esta cuestión desde dentro de los ordenamientos locales, a fin de ver si realmente es posible aplicarlo tal como la Corte y la doctrina dominante pretenden.

Se insiste en que la intención de este trabajo no ha sido responder a las interrogantes planteadas, sino abrir o incentivar el debate a su respecto. Ello, porque, a nuestro juicio, resulta evidente que en virtud del control de convencionalidad no sólo la labor de los jueces nacionales, sino que -a pesar de no haber sido objeto de este estudio- el funcionamiento global de los ordenamientos locales puede verse notablemente afectado, en particular si todas las autoridades e incluso las decisiones democráticas deben someterse al control de convencionalidad. Todo lo dicho tiene importancia, además, por el carácter subsidiario de la labor de la Corte Interamericana, no sólo en cuanto a que ella debe esperar, salvo excepciones, al previo agotamiento de los recursos internos para poder tomar cartas en el asunto, sino más que nada, debido a que para el cumplimiento de sus resoluciones requiere del aparato del Estado. En consecuencia, los problemas que eventualmente ocasionaría el control de convencionalidad dentro de los órdenes internos, podría también afectar la eficacia misma del Derecho Internacional de los Derechos Humanos.

\section{BibliogRAFÍA CITADA}

Aguilar Cavallo, Gonzalo (2012): "El Control de Convencionalidad de los derechos. Comentario a la sentencia de la Corte Suprema de Chile en el caso denominado Episodio Rudy Cárcamo Ruiz de 24.5.12", en Estudios Constitucionales (Año 10 No 2), pp. 717-750.

Aguilar Cavallo, Gonzalo (2009): "La Corte Suprema y la aplicación del Derecho Internacional: un proceso esperanzador", en Estudios Constitucionales (Año 7, No 1), pp. 91-136.

Albanese, Susana (s/f): "La fórmula de la cuarta instancia", pp. 1-12 [fecha de consulta: 20 de noviembre de 2014]. Disponible en LexisNexis, Lexis No $0003 / 001051$.

Amaya Villarreal, Álvaro Francisco (2005) "El principio pro homine: interpretación extensiva vs. el consentimiento del Estado", en International Law. Revista Colombiana de Derecho Internacional, (Vol. 5), pp. 337-380. 
Ayala Corao, Carlos (2012): "Inconstitucionalidad de la denuncia de la Convención Americana sobre Derechos Humanos por Venezuela”, en Estudios Constitucionales (Año 10 No 2), pp. 643-682.

Barbosa Delgado, Francisco R. (2012): "El margen nacional de apreciación en el Derecho Internacional de los Derechos Humanos: entre el estado de derecho y la sociedad democrática”, en Acosta Alvarado, Paola Andrea y NúŇEz Poblete, Manuel (Coords.), El margen de apreciación en el sistema interamericano de derechos humanos: proyecciones regionales y nacionales (México, Unam), pp. 51-82.

BAZÁN, Víctor (2012): "El control de convencionalidad: incógnitas, desafíos y perspectivas", en BAZÁN, Víctor y NASH, Claudio (Eds.), Justicia constitucional y derechos fundamentales. El control de convencionalidad 2011 (Santiago, Konrad Adenauer-Stiftung), pp. 17-55.

BAZÁN, Víctor (2010): "En torno al control de las inconstitucionalidades e inconvencionalidades omisivas", en Anuario de Derecho Constitucional Latinoamericano (Año XVI), Montevideo, pp. 151-177.

BeCERRA Ramírez, Manuel (2009): "La jerarquía de los tratados en el orden jurídico interno. Una visión desde la perspectiva del Derecho Internacional”, en GARCíA Ramírez, Manuel y Castañeda Hernández, Mireya, Recepción nacional del Derecho Internacional de los Derechos Humanos y admisión de la competencia contenciosa de la Corte Interamericana (México, Unam), pp. 291-317.

Becerra Ramírez, José de Jesús y Miranda Camarena, Adrián Joaquín (2013): "El uso del canon internacional de los derechos humanos", en Opinión Jurídica (vol. 12 No 24), pp. 17-34.

Becerra Rojasvértiz, Rubén Enrique (2012): “Enfrentar los desafíos del control de convencionalidad”, en Sufragio (No 8), pp. 20-24.

Benavides Casals, María Angélica (2009): "El consenso y el margen de apreciación en la protección de los derechos humanos", en Ius et Praxis (Año 15 No 1), pp. 295-310.

Bernales Rojas, Gerardo (2007): "La Imprescriptibilidad de la Acción Penal en Procesos por Violaciones a los Derechos Humanos", en Ius et Praxis (Año 13 No 1), pp. 245-265.

BIANCHI, Alberto B. (2010): "Una reflexión sobre el llamado 'control de convencionalidad”, en La Ley No 2010-E, 426, pp. 1-10 [fechadeconsulta:20 dejulio de2015]. Disponible en http://www.joseperezcorti.com.ar/Archivos/DC/Articulos/ Bianchi_Control_de_Convencionalidad_LL_2010.pdf. 
Binder, Christina (2010): “¿Hacia una Corte Constitucional de América Latina? La jurisprudencia de la Corte Interamericana de Derechos Humanos con un enfoque especial sobre las amnistías", en Von Bogdandy, Armin; Ferrer Mac-Gregor, Eduardo y Morales Antoniazzi, Mariela (Coords.), La justicia constitucionaly su internacionalización. ¿Hacia un ius constitutionale commune en América Latina? Tomo II (Traducc. de Gonzalo Aguilar Cavallo y Rebecca Stewart, México, Unam; Max-Plank-Institut für a Usländisches ö Ffentliches Recht und Volkerrecht; Instituto Iberoamericano de Derecho Constitucional), pp. 159-188.

Caballero Juárez, José Antonio (2009): "La recepción de jurisprudencia internacional y la ejecución de fallos en tribunales nacionales. Apuntes para su estudio", en García Ramírez, Sergio y Castañeda Hernández, Mireya (coords.), Recepción nacional del Derecho Internacional de los Derechos Humanos y admisión de la competencia de la Corte Interamericana (México, Unam/Secretaría de Relaciones Exteriores Corte Interamericana de Derechos Humanos), pp. 191-209.

Caballero Ochoa, José Luis (2011): "La cláusula de interpretación conforme y el principio pro persona (art. $1^{\circ}$ segundo párrafo de la Constitución)", en Carbonell Sánchez, Miguel y Salazar Ugarte, Pedro (Coords.), La reforma constitucional de derechos humanos: un nuevo paradigma (México, Unam), pp. 103-133.

Cançado Trindade, Antonio A. (2006): El Derecho Internacional de los Derechos Humanos en el siglo XXI (Santiago, Editorial Jurídica de Chile).

Carbonell, Miguel (s/f): "Introducción general al control de convencionalidad", pp. 67-95 [fecha de consulta: 14 de mayo de 2014]. Disponible en http:// biblio.juridicas.unam.mx/libros/7/3271/11.pdf.

Casal, Jesús M. (s/f): "Algunos desafíos del control de convencionalidad en América Latina” [fecha de consulta: 20 de agosto de 2015]. Disponible en http:// www.ijf.cjf.gob.mx/cursosesp/2012/derhumancontrolconvencionalidad/ Algunos $\% 20 \mathrm{desaf} \% \mathrm{C} 3 \%$ ADos $\% 20 \mathrm{del} \% 20$ control $\% 20 \mathrm{de} \% 20$ convencionalidad\%20en\%20Am\%C3\%A9rica\%20Latina1.pdf.

Castilla JuÁrez, Karlos (2014): "Control de convencionalidad interamericano: una mera aplicación del Derecho Internacional”, en Revista Derecho del Estado (No 33), pp. 149-172.

Castilla JuÁrez, Karlos (2013): “¿Control interno o difuso de convencionalidad? Una mejor idea: la garantía de los tratados”, en Anuario Mexicano de Derecho Internacional (vol. XIII), pp. 51-97. 
Castilla Juárez, Karlos (2011a): "Un nuevo panorama constitucional para el derecho internacional de los derechos humanos en México", en Estudios Constitucionales (Año 9, No 2), pp. 123-164.

Castilla JuÁrez, Karlos (2011b): "El control de convencionalidad; un nuevo debate en México a partir de la sentencia del caso Radilla Pacheco", en Anuario Mexicano de Derecho Internacional (vol. XI), pp. 593-624.

ConTesse, Jorge (2013): “¿La última palabra? Control de convencionalidad y posibilidades de diálogo con la Corte Interamericana de Derechos Humanos", pp. 1-31. Disponible en http://www.law.yale.edu/documents/pdf/sela/ SELA13_Contesse_CV_Sp_20130401.pdf.

Contreras, Pablo (2014): "Control de convencionalidad, deferencia internacional y discreción nacional en la jurisprudencia de la Corte Interamericana de Derechos Humanos", en Ius et Praxis (Año 20 No 2), pp. 235-274.

Contreras, Pablo (2012): Control de convencionalidad fuerte y débil. Parte I [fecha de consulta: 27 de noviembre de 2014]. Disponible en http://diarioconstitucional.cl/articulos/control-de-convencionalidad-fuerte-y-debil-parte-i/.

Del Castillo del Valle, Alberto (s/f): "Control de convencionalidad" [fecha de consulta: 17 de agosto de 2015]. Disponible en Vlex-481695015.

DíAZ Tolosa, Regina Ingrid (2012): "Aplicabilidad en el ámbito interno y en tiempos de paz de las normas de ius cogens del Derecho Internacional Humanitario", en Estudios Constitucionales (Año 10 No 2), pp. 281-322.

DulitzKY, Ariel E. (2015): "An Inter-American Constitutional Court? The Invention of the Conventionality Control by the Inter-American Court of Human Rights", in Texas International Law Journal (vol. 50, Issue 1), pp. 45-93.

DultTzKY, Ariel E. (2014): "El impacto del control de convencionalidad. ¿Un cambio de paradigma en el sistema interamericano de derechos humanos?”, en Rivera, Julio César; Elías, José Sebastián; Grosman, Lucas, Sebastián y Legarre, Santiago (Dirs.), Tratado de los derechos constitucionales (Buenos Aires, Abeledo Perrott), pp. 533-569.

Eva Parada, María José (2006): "Chile ante el Sistema Interamericano: el caso Palamara”, en Anuario de Derechos Humanos (vol. 2), pp. 157-164.

Fernández González, Miguel Ángel (2010): “La aplicación por los tribunales chilenos del derecho internacional de los derechos humanos", en Estudios Constitucionales (Año 8 No 1), pp. 425-442.

Ferrer Mac-Gregor, Eduardo (2014): "Control de convencionalidad (sede interna)”, en Ferrer Mac-Gregor, Eduardo; Martínez Ramírez, Fabiola 
y Figueroa Mejía, Giovanni A. (Coords.), Diccionario de Derecho Procesal Constitucionaly Convencional, segunda edición (México, Unam), pp. 236-240. Ferrer Mac-Gregor, Eduardo (2011): "Interpretación conforme y control difuso de convencionalidad. El nuevo paradigma para el juez mexicano", en Carbonell, Miguel y Salazar, Pedro (Eds.), Derechos humanos; un nuevo modelo constitucional (México, Unam), pp. 339-429.

Ferrer Mac-Gregor, Eduardo (2010): "El control difuso de convencionalidad en el Estado constitucional”, pp. 151-188 [fecha de consulta: 11 de marzo de 2015]. Disponible en http://biblio.juridicas.unam.mx/libros/6/2873/9.pdf.

Ferrer Mac-Gregor, Eduardo y Pelayo Möller, Carlos María (2012): “La obligación de 'respetar' y 'garantizar' los derechos humanos a la luz de la jurisprudencia de la Corte Interamericana”, en Estudios Constitucionales (Año 10 No 2), pp. 141-192.

Galdámez Zelada, Liliana (2007): "Protección de la víctima, cuatro criterios de la Corte Interamericana de Derechos Humanos: interpretación evolutiva, ampliación del concepto de víctima, daño al proyecto de vida y reparaciones", en Revista Chilena de Derecho (vol. 34 No 3), pp. 439-455.

García Pino, Gonzalo (2014): "Preguntas esenciales sobre el control de convencionalidad difuso aplicables a Chile", en Nogueira Alcalá, Humberto (Coord.), La protección de los derechos humanos y fundamentales de acuerdo a la Constitución y el Derecho Internacional de los Derechos Humanos (Santiago, Librotecnia), pp. 355-379.

García Pino, Gonzalo y Contreras Vásquez, Pablo (2014): Diccionario Constitucional Chileno (Santiago, Cuadernos del Tribunal Constitucional No 55).

García Ramírez, Sergio (2011): "El control judicial interno de convencionalidad”, en IUS, Revista del Instituto de Ciencias Jurídicas de Puebla (Año V, No 28), pp. 123-159.

García SAYÁn, Diego (2009): "La recepción del Derecho Internacional de los Derechos Humanos y la jurisprudencia de la Corte Interamericana de Derechos Humanos", en García Ramírez, Sergio y Castañeda Hernández, Mireya (coords.), Recepción nacional del Derecho Internacional de los Derechos Humanos y admisión de la competencia de la Corte Interamericana (México, Unam/Secretaría de Relaciones Exteriores Corte Interamericana de Derechos Humanos), pp. 91-119.

Gómez Robledo, Juan Manuel (2009): "La implementación del Derecho Internacional de los Derechos Humanos en el ámbito interno: una tarea pendiente", en 
García Ramírez, Sergio y Castañeda Hernández, Mireya (coords.), Recepción nacional del Derecho Internacional de los Derechos Humanos y admisión de la competencia de la Corte Interamericana (México, Unam/Secretaría de Relaciones Exteriores Corte Interamericana de Derechos Humanos), pp. 127-150.

Henríquez Viñas, Miriam Lorena (2014): "La polisemia del control de convencionalidad interno", en International Law, Revista Colombiana de Derecho Internacional (vol. 24), pp. 113-341.

Henríquez Viñas, Miriam Lorena (2009): Las fuentes formales del Derecho (Santiago, LegalPublishing).

Henríquez Viñas, Miriam Lorena (s/f): "La oportunidad del control de constitucionalidad de los tratados: improcedencia del control represivo", pp. 1-10. [Fecha de consulta: 5 de agosto de 2014] en Microjuris.com MJCHMDJ193, versión PDF.

HitTers, Juan Carlos (2013): "Un avance en el control de convencionalidad. (El efecto 'erga omnes' de las sentencias de la Corte Interamericana)", en Estudios Constitucionales (Año 11 No 2), pp. 695-710.

HitTERs, Juan Carlos (2012): "El control de convencionalidad y el cumplimiento de las sentencias de la Corte Interamericana", en Estudios Constitucionales (Año 10 No 2), pp. 535-574.

Hitters, Juan Carlos (2009): "Control de constitucionalidad y control de convencionalidad. Comparación (Criterios fijados por la Corte Interamericana de Derechos Humanos)", en Estudios Constitucionales (Año 7 No 2), pp. 109-128.

Hitters, Juan Carlos (2008): “¿Son vinculantes los pronunciamientos de la Comisión y de la Corte Interamericana de Derechos Humanos? (control de constitucionalidad y convencionalidad)", en Revista Iberoamericana de Derecho Procesal Constitucional (No 10, julio-diciembre), pp. 131-156.

IBÁÑEZ RIVAS, Juana María (2012): “Control de convencionalidad: precisiones para su aplicación desde la jurisprudencia de la Corte Interamericana de Derechos Humanos", en Anuario de Derechos Humanos (vol. 8), pp. 103-113.

ÍNiguez MAnso, Andrea Rosario (2014): "El control de convencionalidad en la $\mathrm{CADH}$ y los tribunales chilenos: una tesis de aplicación restrictiva", en Nogueira Alcalá, Humberto (Coord.), La protección de los derechos humanos y fundamentales de acuerdo a la Constitución y el Derecho Internacional de los Derechos Humanos (Santiago, Librotecnia), pp. 381-394.

Juliano, Mario Alberto (2009): "El control de convencionalidad", en Derecho a Réplica. [Fecha de consulta: 28 de mayo de 2015]. Disponible en http://derecho-a-replica.blogspot.com/2009/08/el-control-de-convencionalidad.html. 
León Henríquez, Nicolás (2015): "La acción de inaplicabilidad por inconstitucionalidad sobre los tratados internacionales" (Santiago, Cuadernos del Tribunal Constitucional, No 62).

LONDOÑo LÁZARO, María Cermelina (2010): "El principio de legalidad y el control de convencionalidad de las leyes; confluencias y perspectivas en el pensamiento de la Corte Interamericana de Derechos Humanos", en Boletín Mexicano de Derecho Comparado, nueva serie (Año XLIII, núm. 128), pp. 761-814.

MaLARINo, Ezequiel (2011): “Activismo judicial, punitivización y nacionalización. Tendencias antidemocráticas y antiliberales de la Corte Interamericana de Derechos Humanos", en Grupo Latinoamericano de Estudios sobre Derecho Penal Internacional, Sistema Interamericano de Protección de los Derechos Humanos y Derecho Penal Internacional (Montevideo, Konrad-AdenauerStiftung), pp. 25-61.

Malarino, Ezequiel (2010): "Acerca de la pretendida obligatoriedad de la jurisprudencia de los órganos internacionales de protección de los derechos humanos para los tribunales judiciales nacionales", en Grupo Latinoamericano de Estudios sobre Derecho Penal Internacional, Sistema Interamericano de Protección de los Derechos Humanos y Derecho Penal Internacional (Montevideo, Konrad-Adenauer-Stiftung), pp. 435-455.

Meier García, Eduardo (2011): "Nacionalismo constitucional y Derecho Internacional de los Derechos Humanos", en Estudios Constitucionales (Año 9 No 2), pp. 329-376.

Mejía Lemos, Diego Germán (2014): "On the 'Control de Convencionalidad' Doctrine: a Critical Appraisal of the Inter-American Court of Human Rights' Relevant Case Law", en Anuario Mexicano de Derecho Internacional (vol. XIV), pp. 117-151.

Mora Méndez, Jorge Andrés (2012): "El control de convencionalidad: un replanteamiento de principios y fuentes del Derecho", en Revista Republicana (No 12), pp. 217-237.

Nash Rojas, Claudio (2013): "Control de convencionalidad. Precisiones conceptuales y desafíos a la luz de la jurisprudencia de la Corte Interamericana de Derechos Humanos", en Anuario de Derecho Constitucional Latinoamericano (Año XIX), pp. 489-509.

Nogueira AlcalÁ, Humberto (2013a): "El uso del derecho y jurisprudencia constitucional extranjera de tribunales internacionales no vinculantes por el Tribunal Constitucional chileno en el período 2006-2011", en Estudios Constitucionales (Año 11 No 1), pp. 221-274. 
Nogueira Alcalá, Humberto (2013b): "Diálogo interjurisdiccional y control de convencionalidad entre los tribunales nacionales y la Corte Interamericana de Derechos Humanos en Chile", en Anuario de Derecho Constitucional latinoamericano (Año XIX), pp. 511-553.

Nogueira Alcalá, Humberto (2013c): "El control de convencionalidad y el diálogo interjurisdiccional entre tribunales nacionales y Corte Interamericana de Derechos Humanos", en Revista de Derecho Constitucional Europeo (Año 10 No 19), pp. 221-270.

Nogueira Alcalá, Humberto (2012a): "El uso del derecho convencional internacional de los derechos humanos en la jurisprudencia del Tribunal Constitucional chileno en el período 2006-2010", en Revista Chilena de Derecho (vol. 39 No 1), pp. 149-187.

Nogueira Alcalá, Humberto (2012b): "Los desafíos del control de convencionalidad del corpus iuris interamericano para las jurisdicciones nacionales", en Boletín Mexicano de Derecho Comparado, Nueva Serie (Año XLV, No 135, septiembre-diciembre), pp. 1167-1220.

Nogueira Alcalá, Humberto (2012c): "Diálogo interjurisdiccional, control de convencionalidad y jurisprudencia del Tribunal Constitucional en el período 2006-2011", en Estudios Constitucionales (Año 10 No 2), pp. 57-140.

Nogueira Alcalá, Humberto (2009): "Las mutaciones de la Constitución producidas por vía interpretativa del Tribunal Constitucional. ¿¿El Tribunal Constitucional: poder constituido o poder constituyente en sesión permanente?", en Estudios Constitucionales (Año 7 No 2), 2009, pp. 389-427.

NúNEz Poblete, Manuel (2012): "Sobre la doctrina del margen de apreciación nacional. La experiencia latinoamericana confrontada y el thelos constitucional de una técnica de adjudicación del DIDH", en Acosta Alvarado, Paola Andrea y NúNEzz PoBlete, Manuel (Coords.), El margen de apreciación en el sistema interamericano de derechos humanos: proyecciones regionales y nacionales, (México, Unam), pp. 3-49.

NúNEzZ Poblete, Manuel (2011): "Principios metodológicos para la evaluación de los acuerdos aprobatorios de los tratados internacionales de derechos humanos y de las leyes de ejecución de obligaciones internacionales en la misma materia", en Hemiciclo, Revista de Estudios Parlamentarios (Año 2 No 4), pp. 51-81.

NúNEz Poblete, Manuel (2010): "Sobre la declaración de inaplicabilidad de los tratados internacionales. Un estudio en defensa de su fundamento y legitimidad", en Estudios Constitucionales (Año 8 No 2), pp. 461-464. 
NúÑez Poblete, Manuel (2008): "Introducción al concepto de identidad constitucional y a su función frente al derecho supranacional e internacional de los derechos de la persona", en Ius et Praxis (Año 14 No 2), pp. 331-372.

Orozco Henríquez, José de Jesús (2011): "Los derecho humanos y el nuevo artículo $1^{\circ}$ constitucional”, en IUS, Revista del Instituto de Ciencias Jurídicas de Puebla (Año V, No 28), pp. 85-98.

PAúl DíAz, Álvaro (2013): "La Corte Interamericana in vitro: notas sobre su proceso de toma de decisiones a propósito del caso Artavia", Revista Derecho Público Iberoamericano, Universidad del Desarrollo (Año 1 No 2), pp. 303-345.

Pereyra Zabala, Gastón (2011): "El control de convencionalidad en el sistema interamericano de derechos humanos", en Revista de Derecho, Montevideo (No 6), pp. 155-176.

Rey CANTOR, Ernesto (2008): "Controles de convencionalidad de las leyes", en Ferrer Mac-Gregor, Eduardo y Zaldívar Lelo de Larrea, Arturo (Coords.), La Ciencia del Derecho Procesal Constitucional. Estudios en homenaje a Héctor Fix Zamudio en sus cincuenta años como investigador del derecho, Vol. IX Derechos Humanos y Tribunales Internacionales (México, Unam, Instituto Mexicano de Derecho Procesal Constitucional, Marcial Pons), pp. 225-262.

Rey Cantor, Ernesto y Rey Amaya, Ángela Margarita (2014): "Control de convencionalidad, test de", en Ferrer Mac-Gregor, Eduardo; Martínez Ramírez, Fabiola y Figueroa Mejía, Giovanni A. (Coords.), Diccionario de Derecho Procesal Constitucional y Convencional, segunda edición (México, Unam/Secretaría de Relaciones Exteriores Corte Interamericana de Derechos Humanos), pp. 240-242.

Rodríguez Morelión, María Engracia del Carmen (2009): "La recepción de la jurisprudencia interamericana de derechos humanos", en GARCíA RAMíREZ, Manuel y Castañeda Hernández, Mireya (Coords.), Recepción nacional del Derecho Internacional de los Derechos Humanos y admisión de la competencia contenciosa de la Corte Interamericana (México, Unam), pp. 347-379.

SAGÜÉs, Néstor P. (2014a): "Constitución convencionalizada", en FERrER MACGregor, Eduardo; Martínez Ramírez, Fabiola y Figueroa Mejía, Giovanni A. (Coords.), Diccionario de Derecho Procesal Constitucional y Convencional, segunda edición (México, Unam), pp. 190-192.

SAGÜÉS, Néstor P. (2014b): "Control constructivo (positivo) de convencionalidad", en Ferrer Mac-Gregor, Eduardo; Martínez Ramírez, Fabiola y Figueroa MejíA, Giovanni A. (Coords.), Diccionario de Derecho Procesal Constitucional y Convencional, segunda edición (México, Unam), pp. 222-224. 
SAGÜÉs, Néstor P. (2014c): "Derechos constitucionales y derechos humanos. De la Constitución Nacional a la Constitución 'convencionalizada", en NogUEIRA AlCalÁ, Humberto (Coord.), La protección de los derechos humanos y fundamentales de acuerdo a la Constitución y el Derecho Internacional de los Derechos Humanos (Santiago, Librotecnia), pp. 15-23.

SAGÜÉs, Néstor P. (2012a): "El poder constituyente como intérprete de la Constitución”, en Pensamiento Constitucional (No 16, enero 2012), pp. 1-10. [Fecha de consulta: 11 de marzo de 2015]. Disponible en http://vlex.com/ $\mathrm{vid} /$ poder-constituyente-interprete-constitucion-411847706.

SAGÜÉS, Néstor P. (2012b): "Derecho internacional y derecho constitucional. Dificultades operativas del control de convencionalidad en el sistema interamericano", en Ahrens, Helen (Comp.), El Estado de derecho en América Latina. Libro homenaje a Horst Schönbolhm (México D.F., Konrad Adenauer Stiftung, e. v.), pp. 21-29.

SAGÜÉs, Néstor P. (2010): "Obligaciones internacionales y control de convencionalidad”, en Estudios Constitucionales (Año 8 No 1), pp. 117-136.

SAGÜÉs, Néstor P. (2009): "El 'control de convencionalidad' en particular sobre las constituciones nacionales", en La Ley, 19/02/2009, 1, pp. 1-7 [fecha de consulta: 6 de marzo de 2015]. Disponible en http://www.joseperezcorti.com.ar/ Archivos/DC/Articulos/Sagues_Control_de_Convencionalidad_LL_2009.pdf.

SAGÜÉs, Néstor P. (2003): "Las relaciones entre los tribunales internacionales y los tribunales nacionales en materia de derechos humanos. Experiencias en Latinoamérica”, en Ius et Praxis (Año 9 No 1), pp. 205-221.

SAGÜÉs, Néstor P. (s/f a): "El 'Control de convencionalidad' como instrumento para la elaboración de un ius commune interamericano", pp. 449-468 [fecha de consulta: 7 de mayo de 2014]. Disponible en http://biblio.juridicas.unam. $\mathrm{mx} / \mathrm{libros} / 6 / 2895 / 15$.pdf.

SAGÜÉs, Néstor P. (s/f b): "El 'control de convencionalidad' en el sistema interamericano y sus anticipos en el ámbito de los derechos económico-sociales. Concordancias y diferencias con el sistema europeo", pp. 381-417 [fecha de consulta: 27 de marzo de 2014]. Disponible en http://biblio.juridicas.unam. $\mathrm{mx} /$ libros/7/3063/16.pdf.

Santiago, Alfonso (2009): "El Derecho Internacional de los Derechos Humanos: posibilidades, problemas y riesgos de un nuevo paradigma jurídico", en Persona y Derecho (Vol. 60), pp. 91-130.

VÁsquez, Luis Daniel y Serrano, Sandra (2011), "Los principios de universalidad, interdependencia, indivisibilidad y progresividad. Apuntes para su aplicación 
práctica”, en Carbonell, Miguel y Salazar, Pedro (Coords.), La reforma constitucional en derechos humanos: un nuevo paradigma (México, Unam), pp. 135-165.

\section{DOCUMENTOS INTERNACIONALES CITADOS}

A) Sentencias de la Corte Interamericana

Caso Almonacid Arellano y otros vs. Chile. Excepciones Preliminares, Fondo, Reparaciones y Costas. Sentencia de 26 de septiembre de 2006. Serie C No 154.

Caso Trabajadores Cesados del Congreso (Aguado Alfaro y otros) vs. Perú. Excepciones Preliminares, Fondo, Reparaciones y Costas. Sentencia de 24 de noviembre de 2006. Serie C No 158.

Caso Gelman vs. Uruguay. Fondo y Reparaciones. Sentencia de 24 de febrero de 2011. Serie C No 221.

Caso Gelman vs. Uruguay. Supervisión de cumplimiento de sentencia. Resolución de 20 de marzo de 2013.

Caso López Lone y Otros vs. Honduras (Excepción Preliminar, Fondo, Reparaciones $y$ Costas). Sentencia de 5 de octubre de 2015. Serie C No 302.

B) Votos razonados, concurrentes o disidentes

Voto Razonado del juez ad hoc Roberto de Figueiredo Caldas en Corte IDH, Caso Gomes Lund y Otros ("Guerrilha do Araguaia") vs. Brasil. Sentencia de 24 de noviembre de 2010. Serie C No 219.

Voto Razonado del juez ad hoc Eduardo Ferrer Mac-Gregor Poisot en Corte IDH, Caso Cabrera García y Montiel Flores vs. México. Sentencia de 26 de noviembre de 2010. Serie C No 220.

Voto Razonado del juez Eduardo Ferrer Mac-Gregor Poisot en Corte IDH, Caso Gelman vs. Uruguay. Supervisión de cumplimiento de sentencia. Resolución de 20 de marzo de 2013.

Voto Concurrente del juez Eduardo Ferrer Mac-Gregor Poisot en Corte IDH, Caso Liakat Ali Alibux vs. Suriname. Sentencia de 30 de enero de 2014. Serie C No 276.

C) Opiniones Consultivas

Corte IDH. Derechos y garantías de niñas y niños en el contexto de la migración y/o en necesidad de protección internacional. Opinión Consultiva OC-21/14, de 19 de agosto de 2014. Serie A No 21. 